Article

\title{
Top-Down Proteomics of Medicinal Cannabis
}

\author{
Delphine Vincent ${ }^{1, *}$, Steve Binos ${ }^{2}$, Simone Rochfort ${ }^{1}$ and German Spangenberg ${ }^{1}$ \\ 1 Agriculture Victoria Research, AgriBio, Centre for AgriBioscience, Bundoora, Victoria 3083, Australia; \\ simone.rochfort@agriculture.vic.gov.au (S.R.); german.spangenberg@agriculture.vic.gov.au (G.S.) \\ 2 Thermo Fisher Scientific, Bio21 Institute, The University of Melbourne, 30 Flemington Rd, Parkville, \\ Victoria 3052, Australia; steve.binos@thermofisher.com \\ * Correspondence: delphine.vincent@djpr.vic.gov.au; Tel.: +61-3-90327116
}

Received: 29 July 2019; Accepted: 20 September 2019; Published: 24 September 2019

\begin{abstract}
The revised legislation on medicinal cannabis has triggered a surge of research studies in this space. Yet, cannabis proteomics is lagging. In a previous study, we optimised the protein extraction of mature buds for bottom-up proteomics. In this follow-up study, we developed a top-down mass spectrometry (MS) proteomics strategy to identify intact denatured protein from cannabis apical buds. After testing different source-induced dissociation (SID), collision-induced dissociation (CID), higher-energy collisional dissociation (HCD), and electron transfer dissociation (ETD) parameters on infused known protein standards, we devised three LC-MS/MS methods for top-down sequencing of cannabis proteins. Different MS/MS modes produced distinct spectra, albeit greatly overlapping between SID, CID, and HCD. The number of fragments increased with the energy applied; however, this did not necessarily translate into greater sequence coverage. Some precursors were more amenable to fragmentation than others. Sequence coverage decreased as the mass of the protein increased. Combining all MS/MS data maximised amino acid (AA) sequence coverage, achieving $73 \%$ for myoglobin. In this experiment, most cannabis proteins were smaller than $30 \mathrm{kD}$. A total of 46 cannabis proteins were identified with 136 proteoforms bearing different post-translational modifications (PTMs), including the excision of N-terminal $\mathrm{M}$, the N-terminal acetylation, methylation, and acetylation of $\mathrm{K}$ resides, and phosphorylation. Most identified proteins are involved in photosynthesis, translation, and ATP production. Only one protein belongs to the phytocannabinoid biosynthesis, olivetolic acid cyclase.
\end{abstract}

Keywords: infusion; LC-MS; LC-MS/MS; SID; CID; HCD; ETD; PTMs; apical bud; cannabis intact proteins; protein standards; proteoforms; top-down sequencing; Prosight Lite; Mascot

\section{Introduction}

The state of Victoria in Australia was the first jurisdiction to legalise access to medicinal cannabis under the Medicinal Cannabis Act in 2016 (www2.health.vic.gov.au). In this context, we have controlled access to medicinal cannabis material grown to full maturity in the state-of-the-art Victorian government medicinal cannabis cultivation facility. Utilizing this asset, we developed analytical methods for bottom-up proteomics of mature buds [1] and cannabinoid quantitation from cannabis resin [2]. A wealth of information pertaining to botany, phytochemistry, biology, and medicinal properties of Cannabis sativa has been accumulated over the years since the abolition of the legal use of cannabis in 1937 [3,4]. Recent phylogenetics studies have redefined the Cannabaceae family to now include not only Cannabis and Humulus (hop) but also eight genera formerly assigned to the Celtidaceae family: Celtis, Pteroceltis, Aphananthe, Chaetachme, Gironniera, Lozanella, Trema, and Parasponia [5]. Other closely related families are Moraceae and Urticaceae, which comprise Boehmeria nivea (Chinese grass). A search for amino acid (AA) sequences in UniprotKB database (www.uniprot.org) using the key word "Cannabis sativa" retrieves entries from not only $C$. sativa and subspecies but also from closely related species 
Humulus lupulus, Humulopsis scandens, Humulus yunnanensis, and Boehmeria nivea (also called Urtica nivea). Another well studied area of research relates to the discovery of $C$. sativa active components, phytocannabinoids [6-8], and the elucidation of their biosynthetic pathway [9,10]. Owing to the change in legislation in the 1990s, an exponential surge of cannabis studies can be seen with close to 20,000 publications to date listed in Pubmed (www.ncbi.nlm.nih.gov/pubmed). The most dynamic field of cannabis research now targets medical applications. Proteomics research on C. sativa is greatly lagging behind, with only nine reports thus far. Five studies processed nonreproductive organs from immature cannabis plants such as roots [11], hypocotyls [12], and leaves [13] or processed seeds from hemp [14,15]. To our knowledge, only four proteomics reports have been published thus far on reproductive organs from C. sativa. Raharjo and colleagues in 2004 published proteomics results on flowers and glands from cannabis plants [16]. Ten years later, Happyana produced his $\mathrm{PhD}$ thesis on cannabis trichomes [17], and preliminary results from Jenkins and Osburn were very recently made available on the bioRxiv preprint server [18]. Early this year, we published results on shotgun proteomics [1] in which we demonstrated the superiority of protein extraction from C. sativa mature buds using a guanidine-hydrochloride buffer over a urea-based solution.

The term proteoforms, coined in 2016 [19], corresponds to all of the different molecular forms in which the protein product of a single gene can be found; this includes all forms of genetic variation, alternative splicing of RNA transcripts, and post-translational modifications (PTMs). Typical PTMs include phosphorylations, glycosylations, oxidations, and $\mathrm{N}$-terminus acetylations [20]. Top-down proteomics describes the analysis of intact proteins, either in their native form or more often in a denatured state, which allows for a characterisation of proteoforms as comprehensive as possible [21]. Whilst gel-based proteomics such as two-dimensional electrophoresis technically fit within this definition, top-down proteomics is typically performed using gel-free- and mass spectrometry (MS)-based strategies, along with the acquisition of MS/MS spectra for sequencing purposes. A literature search within Pubmed using the key words "top-down proteomics" listed 713 publications from 2000 until 12 June 2019, including 130 reviews. The number of publications in this space is on the rise, with only a handful in the early 2000s and 82 articles in 2018. This year, already 46 papers are available in this field. Such is the interest in this emerging field that a Consortium for Top-Down Proteomics (CTDP, http://topdownproteomics.org/) was created in 2014 [22] making available relevant documentation and online resources. This consortium standardized the notation of proteoforms [23] and just released some excellent guidelines for TDP [24].

Current MS/MS fragmentation methods include collision-induced dissociation (CID), in-source CID (also known as source-induced dissociation, SID), higher-energy collisional dissociation (HCD), electron capture dissociation (ECD), electron transfer dissociation (ETD), and ultraviolet photodissociation (UVPD). Combining various fragmentation modes improves top-down sequencing outcomes, as different types of fragment ions are generated. For instance, SID, CID, and HCD create b- and y-type ions, while ETD creates c- and z-type ions. Extensive AA sequence coverage of known intact proteins was achieved through efficient multimodal gas-phase fragmentation and sophisticated computational analysis [25]. Top-down proteomic experiments are challenging for the following reasons: low abundance of many proteoforms and low signal-to-noise $(\mathrm{S} / \mathrm{N})$ ratios inherent to mass measurement of large molecules, data analysis of complex MS and MS/MS spectra, and co-elution of proteoforms during the initial online separation stage by liquid chromatography (LC) or capillary zone electrophoresis (CZE) [20]. Proteoforms whose molecular weights (MW) exceed $\sim 50-70 \mathrm{kDa}$ remain difficult to top-down sequence due to limitations inherent to MS and the need for improved separations. New generation instruments such as the 21 Tesla Fourier transform ion cyclotron resonance (21T FT-ICR) mass spectrometer, offering extended mass ranges combined with recording short time-domain transients to maximise spectral signal-to-noise ratio $(\mathrm{S} / \mathrm{N})$ of large proteoforms, could alleviate these issues [26]. Given the paucity of top-down proteomics reports on plants species, it seems the technical challenges are even greater for samples originating from plants. 
We previously published three studies on top-down proteomics of bovine milk samples using ultra-performance liquid chromatography (UPLC) online with a quadrupole time-of-flight (Q-ToF) mass spectrometer offering a 60,000 resolving power [27-29]. In these reports, major known milk proteins were targeted by first optimizing analytical methods on purchased standards and validating them on milk samples $[28,29]$ and then applying the optimum method to a study aimed at exploring UHT milk (long life, ultra-heat treatment applied) properties during shelf-life storage [27]. Top-down sequencing information was obtained from CID and/or in-source CID experiments, which were the only fragmentation modes offered by this Q-ToF mass spectrometer. Data analysis proved particularly challenging, as we did not have the proprietary software from the mass spectrometer's manufacturer required to annotate MS/MS data in an automated fashion. Ultimately, we used the Genedata Expressionist software to develop workflows, allowing us to automate batch processing and annotation of both LC-MS and LC-MS/MS data [29]. This led to the discovery of extensive proteolysis of milk major proteins-in particular, beta- and alpha-S1-caseins-during the one-year storage of UHT milk [27]. Our experience on samples sourced from animals led us to tackling a top-down proteomics study on plant tissues. This work follows on from our optimization of protein extraction of mature buds from medicinal cannabis prior to bottom-up proteomics [1]. In this top-down study, we used a hybrid mass spectrometer composed of a linear ion trap (LTQ or ITMS) and a Fourier-transform Orbitrap (FTMS), which we typically use for bottom-up experiments $[1,30]$. This powerful instrument offers high resolution (up to 240,000) and multiple modes of fragmentations (SID, CID, HCD, and ETD) relative to the Q-ToF system employed previously.

In a first step, we benchmarked our analytical workflow-in particular, MS and data mining —using readily available proteins. To this end, we infused known protein standards of various MWs, namely myoglobin $17 \mathrm{kD}$, alpha-casein $(\alpha-\mathrm{CN}) 24 \mathrm{kD}$, beta-lactoglobulin ( $\beta-\mathrm{LG}) 19 \mathrm{kD}$, and bovine serum albumin (BSA, $67 \mathrm{kD}$ ), and applied different MS/MS modes at increasing energy levels to assess fragmentation efficiency across different proteins and charge states of precursor ions. Our results show that different MS/MS modes produced distinct spectra, albeit greatly overlapping between SID, CID, and HCD, as they produced the same b- and y-types of ions. The number of fragment ions increased with the energy applied; however, this did not necessarily translate into greater sequence coverage. We also indicate that some precursors were more amenable to fragmentation than others, and that sequence coverage decreased as the mass of the protein increased. Combining all MS/MS data maximised AA sequence coverage, and processing it using ProSight Lite software yielded up to $73 \%$ for myoglobin, $56 \%$ for $\beta-\mathrm{LG}, 41 \%$ for $\alpha-\mathrm{S} 1-\mathrm{CN}$, and $6 \%$ for BSA. These initial tests helped us refine the methods to top-down sequence intact protein extracts from cannabis buds in triplicate. Following an extended 120 min separation by LC, intact denatured cannabis proteins were analysed by FTMS with the highest resolution in duplicate. They were then analysed by FTMS/MS using three methods in succession applying "low", "medium", and "high" energy levels for ETD, CID, and HCD modes. In this experiment, most cannabis proteins were smaller than $30 \mathrm{kD}$. Several databases were searched, more or less extensively and specifically, with more or less stringent tolerance. Out of the 11,250 MS/MS spectra generated and searched using the most specific database and highest stringency, only 258 $(2 \%)$ were annotated, amounting to 46 protein accessions and detecting various PTMs (oxidation, methylation, acetylation, phosphorylations). Our results are discussed hereafter.

\section{Materials and Methods}

The experimental design is schematised in Figure 1. 
A

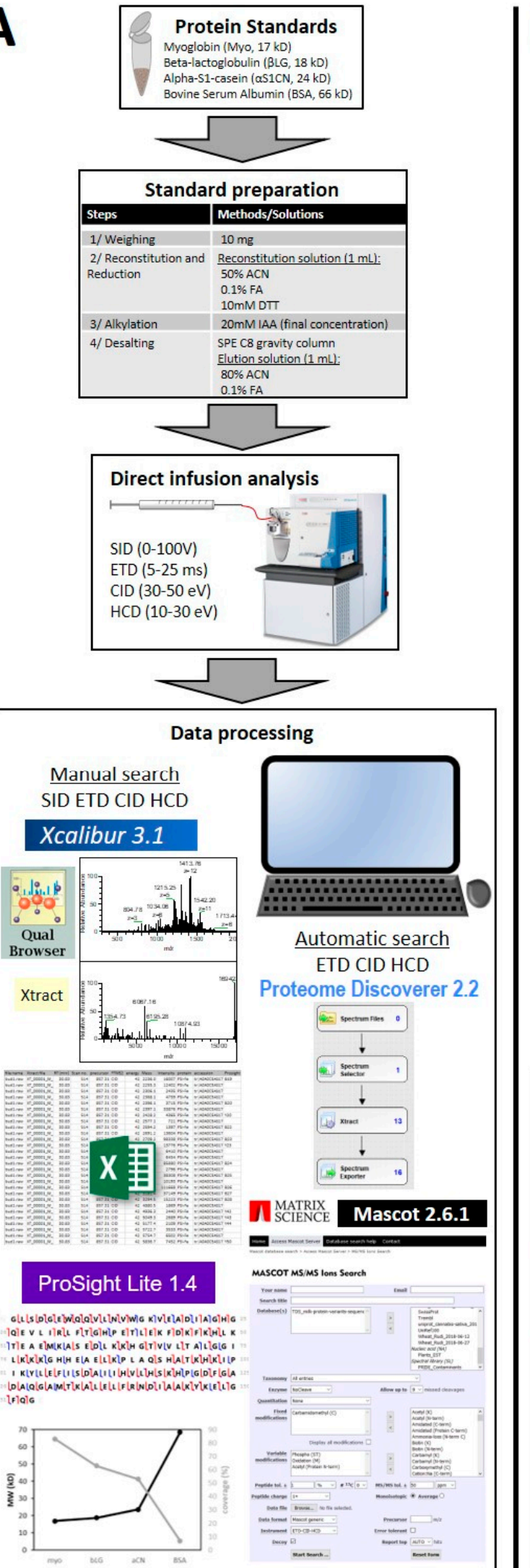

B

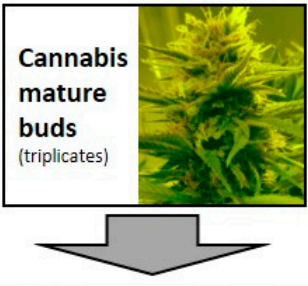

Protein extraction

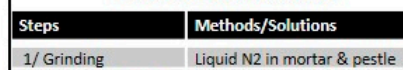

1/ Grinding Liquid 2 in mortar \&
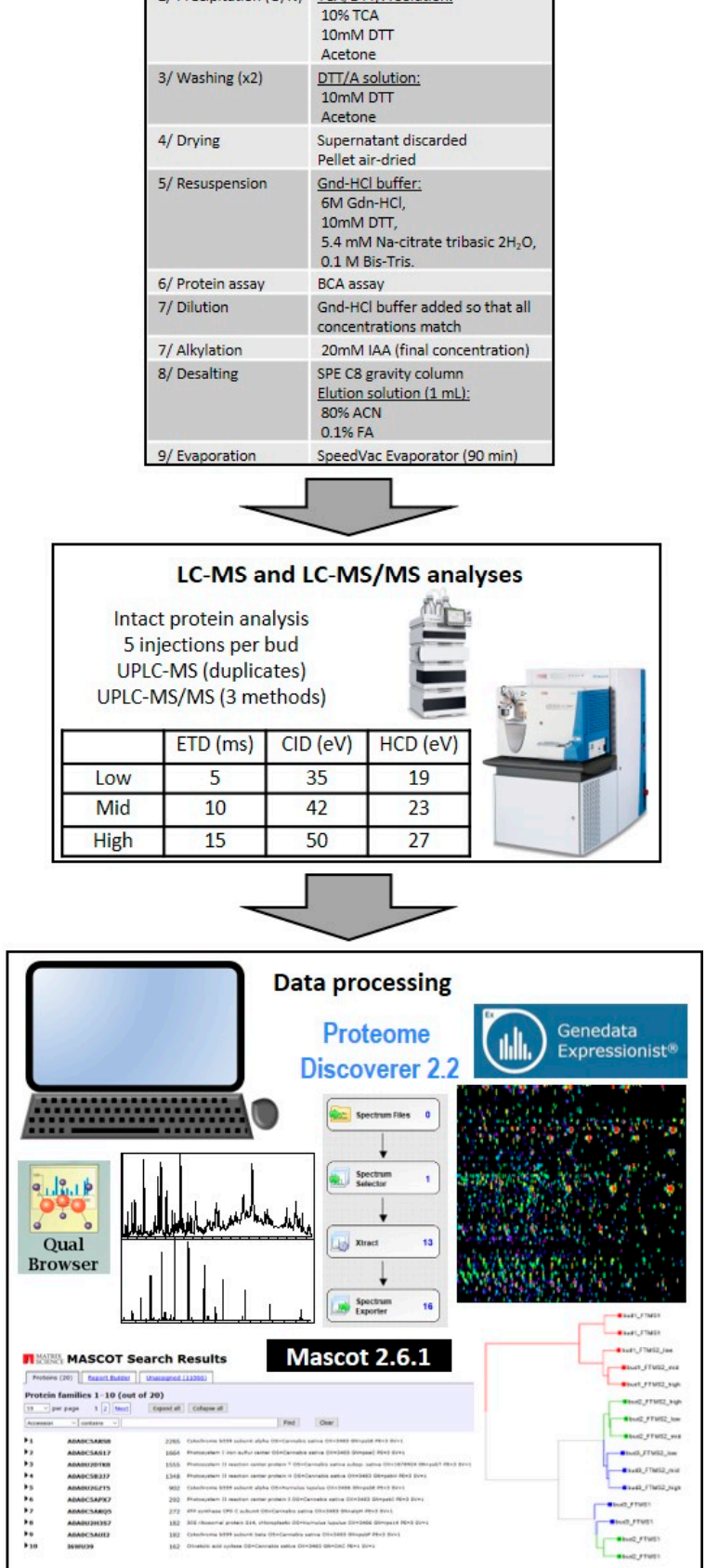

Figure 1. Experimental design. (A) Processing of known protein standards; (B) processing of cannabis bud samples. 


\subsection{Protein Standards}

\subsubsection{Standard List}

The protein standards were all purchased from Sigma and included: $\alpha$-casein $(\alpha-\mathrm{CN} 23.6 \mathrm{kDa})$ from bovine milk (C6780-250MG, 70\% pure), $\beta$-lactoglobulin ( $\beta$-LG, $18.7 \mathrm{kDa}$ ) from bovine milk (L3908-250MG, 90\% pure), albumin from bovine serum (BSA, $66.5 \mathrm{kDa}, \mathrm{A} 7906-10 \mathrm{G}, 98 \%$ pure), and myoglobin from horse skeletal muscle (Myo, $16.9 \mathrm{kDa}, \mathrm{M0630-250MG}, 95-100 \%$ pure and salt-free) $[28,29]$.

\subsubsection{Standard Preparation}

These lyophilized protein standards were fully solubilised at a $10 \mathrm{mg} / \mathrm{mL}$ concentration in $50 \%$ acetonitrile (ACN)/0.1\% formic acid (FA)/10 mM dithiothreitol (DTT). Standards were dissolved by vortexing for $1 \mathrm{~min}$ and sonication for $10 \mathrm{~min}$ followed by another $1 \mathrm{~min}$ vortexing. Iodoacetamide (IAA) was added to reach a final concentration of $20 \mathrm{mM}$, vortexed for $1 \mathrm{~min}$, and left to incubate for $30 \mathrm{~min}$ at room temperature in the dark. Apart from BSA and $\beta$-lactoglobulin, none of the standards needed reduction and alkylation steps, as they had no disulfide bridges; yet, these steps were still performed to emulate plant sample processing.

Standard solutions were then desalted using solid phase extraction (SPE) cartridges (Sep-Pak C18 1cc Vac Cartridge, $50 \mathrm{mg}$ sorbent, 55-105 $\mu \mathrm{m}$ particle size, $1 \mathrm{~mL}$, Waters, Milford, MA, USA) by gravity as described in [30]. Bound intact proteins were desalted using $1 \mathrm{~mL}$ of $0.1 \%$ FA solution and eluted into a $2 \mathrm{~mL}$ microtube using $1 \mathrm{~mL}$ of $80 \% \mathrm{ACN} / 0.1 \%$ FA solution.

\subsection{Plant Materials}

\subsubsection{Cannabis Sampling and Grinding}

Fresh plant material was obtained from the Victorian Government Medicinal Cannabis Cultivation Facility. The top three centimeters of the mature apical bud were excised using secateurs, placed into a labelled paper bag, snap frozen in liquid nitrogen, and stored at $-80{ }^{\circ} \mathrm{C}$ until grinding. Samples were collected in triplicate.

Frozen buds were ground in liquid nitrogen using a mortar and pestle. The ground frozen powder was transferred into a $15 \mathrm{~mL}$ tube and stored at stored at $-80^{\circ} \mathrm{C}$ until protein extraction.

\subsubsection{Cannabis Protein Extraction}

Protein extraction for cannabis mature apical buds was previously optimized [1], with the method referred to as "Extraction 4" yielding the best results. This method was upscaled as detailed below.

One $500 \mathrm{mg}$ scoop of ground frozen powder was transferred into a $15 \mathrm{~mL}$ tube kept on ice prefilled with $12 \mathrm{~mL}$ ice-cold 10\% trichloroacetic acid (TCA)/10mM dithiothreitol (DTT)/acetone $(w / w / v)$. The tubes were vortexed for $1 \mathrm{~min}$ and left at $-20^{\circ} \mathrm{C}$ overnight. The next day, tubes were centrifuged for $30 \mathrm{~min}$ at $4{ }^{\circ} \mathrm{C}$ and at maximum speed (5000 rpm) using a swing rotor centrifuge (Sigma, (Australia) 4-16 k). The supernatant was removed, and the pellet was resuspended in $12 \mathrm{~mL}$ ice-cold $10 \mathrm{mM}$ DTT/acetone $(w / v)$ by vortexing for $1 \mathrm{~min}$. Tubes were left at $-20^{\circ} \mathrm{C}$ for $2 \mathrm{~h}$. The tubes were centrifuged as specified before, and the supernatant was removed. This washing step of the pellet was repeated once more. The pellets were dried for 30 min under a fume hood. The dry pellet was resuspended in $2 \mathrm{~mL}$ of guanidine- $\mathrm{HCl}$ buffer ( $6 \mathrm{M}$ guanidine- $\mathrm{HCl}, 10 \mathrm{mM}$ DTT, $5.37 \mathrm{mM}$ sodium citrate tribasic dihydrate and $0.1 \mathrm{M}$ Bis-Tris).

\subsubsection{Protein Assay and Cannabis Protein Alkylation}

Protein extracts from apical buds were diluted ten times into guanidine- $\mathrm{HCl}$ buffer. The protein concentrations were measured in triplicate using the Microplate BCA protein assay kit (Thermo Scientific, MA, USA) following the manufacturer's instructions. Bovine serum albumin (BSA) from 
the kit was used as a standard as per instructions. Protein extract concentrations ranged from 2.84 to $3.72 \mathrm{mg}$ of proteins per $\mathrm{mL}$ of extract.

Following protein assay, the concentrations of the DTT-reduced protein samples were adjusted to that of the least concentrated $(2.84 \mathrm{mg} / \mathrm{mL})$ by adding the appropriate volume of guanidine- $\mathrm{HCl}$ buffer. The protein extracts were then alkylated by adding a volume of $1 \mathrm{M}$ iodoacetamide (IAA)/water $(w / v)$ solution to reach a $20 \mathrm{mM}$ final IAA concentration. The tubes were vortexed for $1 \mathrm{~min}$ and left to incubate at room temperature in the dark for $60 \mathrm{~min}$.

\subsubsection{Cannabis Protein Desalting and Evaporation}

A volume of $0.5 \mathrm{~mL}$ of alkylated protein extract (1.42 $\mathrm{mg}$ proteins) was then desalted as described above in Section 2.1.2.

The $1 \mathrm{~mL}$ eluates were then evaporated using a SpeedVac concentrator (Savant SPD2010, Thermo Scientific, Waltham, MA, USA) for $90 \mathrm{~min}$ until the volume reached $0.2 \mathrm{~mL}$. The evaporated samples were transferred into a $100 \mu \mathrm{L}$ glass insert placed into a glass vial. The vials were positioned into the autosampler at $4{ }^{\circ} \mathrm{C}$ for immediate analyses by UPLC-MS.

\subsection{Mass Spectrometry Analyses}

MS analyses were performed on an Orbitrap Elite hybrid ion trap-Orbitrap mass spectrometer (Thermo Scientific, MA, USA) composed of a linear ion trap quadrupole (ITMS) mass spectrometer hosting the source and a Fourier transform mass spectrometer (FTMS) with a resolution of 240,000 at $400 \mathrm{~m} / \mathrm{z}$. Both ITMS and FTMS were calibrated in positive mode, and the ETD was tuned prior to all MS and MS/MS experiments. All MS and MS/MS files [RAW, mzXML, Mascot Generic Format (MGF)] and FASTA files from known protein standards and cannabis samples are available from the stable public repository MassIVE at the following URL: http://massive.ucsd.edu/ProteoSAFe/datasets.jsp with the accession number MSV000083970.

\subsubsection{Infusion of Protein Standards and Analyses by Mass Spectrometry}

Protein standard solutions were individually infused using a $0.5 \mathrm{~mL}$ Gastight \#1750 syringe (Hamilton Co.) at a 20-30 $\mu \mathrm{L} / \mathrm{min}$ flow rate using the built-in syringe pump of the LTQ mass spectrometer to achieve at least $1 \mathrm{e} 6$ ion signal intensity. Protein standard solutions were first pushed through $30 \mathrm{~cm}$ of red PEEK tubing (0.005 in ID) and then through a metal union and a PEEK VIPER tube $(6041-5616,130 \mu \mathrm{m} \times 150 \mathrm{~mm}$, Thermo Fischer Scientific) to the heated electrospray ionisation (HESI) source where proteins were ionized through a HESI needle insert 0.32 gauge (Thermo Fisher Scientific 70005-60155).

The source parameters were: capillary temperature $300{ }^{\circ} \mathrm{C}$, source heater temperature $250{ }^{\circ} \mathrm{C}$, sheath gas flow 30, auxillary gas flow 10, sweep gas flow 2, FTMS injection waveforms on, FTMS full AGC target 1e6, FTMS MSn AGC target 1e6, positive polarity, source voltage $4 \mathrm{kV}$, source current $100 \mu \mathrm{A}$, S-lens RF level 70\%, reagent ion source CI pressure 10, reagent vial ion time $200 \mathrm{~ms}$, reagent vial AGC target 5e5, supplemental activation energy 15V, FTMS full micro scans 16, FTMS full max ion time 100 ms, FTMS MSn micro scans 8, and FTMS MSn max ion time $1000 \mathrm{~ms}$. SID was set at $15 \mathrm{~V}$, and FT Penning gauge pressure difference was set at $0.01 \mathrm{E}-10$ Torr to improve signal intensity. The scanning mass windows were 600-2000 m/z for FTMS1 and 300-2000 m/z for FTMS2.

Various fragmentation parameters were tested on individual protein standards, including in-source fragmentation (SID) potentials from 0 to $100 \mathrm{~V}$ (maximum potential). Collision-induced dissociation (CID) normalized collision energy (NCE) varied from 30 to $50 \mathrm{eV}$ with constant activation $\mathrm{Q}$ of 0.400 and an activation time of $100 \mathrm{~ms}$. High energy CID (HCD) NCE varied from 10 to $30 \mathrm{eV}$ with constant activation time of $0.1 \mathrm{~ms}$. Electron transfer dissociation (ETD) activation times varied from 5 to $25 \mathrm{~ms}$ with constant activation $Q$ of 0.250 . Data files were acquired on the fly using the Acquire Data function of Tune Plus software 2.7 (Thermo Fisher Scientific) for up to $3 \mathrm{~min}$ at a time. 
2.3.2. Separation of Cannabis Intact Proteins by Ultra-Performance Liquid Chromatography (UPLC)

Intact proteins from cannabis mature buds were chromatographically separated using a UPLC 1290 Infinity Binary LC system (Agilent, Santa Clara, CA, USA) and a bioZen XB-C4 column $(3.6 \mu \mathrm{m}$, $200 \AA, 150 \times 2.1 \mathrm{~mm}$, Phenomenex, Torrance, CA, USA) kept at $90^{\circ} \mathrm{C}$. Flow rate was $0.2 \mathrm{~mL} / \mathrm{min}$, and total duration was $120 \mathrm{~min}$. Mobile phase A contained $0.1 \%$ FA in water, and mobile phase B contained $0.1 \% \mathrm{FA}$ in acetonitrile.

Chromatographic separation was optimized (data not shown), and optimum UPLC gradient for cannabis proteins was as follows: starting conditions $3 \% \mathrm{~B}$, ramping to $15 \% \mathrm{~B}$ in $2 \mathrm{~min}$, ramping to $40 \%$ B in $89 \mathrm{~min}$, ramping to $50 \%$ B in $5 \mathrm{~min}$, ramping to $99 \%$ B in $5 \mathrm{~min}$ and held at $99 \%$ B for $10 \mathrm{~min}$, lowering to $3 \% \mathrm{~B}$ in $1.1 \mathrm{~min}$, equilibration at $3 \%$ B for $7.9 \mathrm{~min}$. A $20 \mu \mathrm{L}$ injection volume was applied to each protein extract. Each extract was injected five times with blanks in between.

\subsubsection{Analyses of Cannabis Intact Protein Extracts using Mass Spectrometry online with UPLC}

The UPLC outlet line was connected to the switching valve of the LTQ mass spectrometer. During the 119 min mass spectrometry (MS) acquisition time, the first two minutes and the last minute of the run were directed to the waste, whereas the rest of the run was directed to the source.

\section{Full Scan FTMS1}

Tune parameters were described above. Data were acquired in positive polarity with profile and normal scan modes at a resolution of 240,000 at $400 \mathrm{~m} / \mathrm{z}$ along a mass window of 500-2000 m/z. SID was set at $15 \mathrm{~V}$. Full scan files were acquired in duplicate at the first and the last injections of the 5 sample injections. The three intermediate injections were dedicated to tandem MS (see below).

\section{FTMS2}

Three MS/MS methods were applied in which the energy applied to each fragmentation modes varied between what we referred to as "low", "high", and "mid" (intermediate). SID was set to $15 \mathrm{~V}$ throughout. One segment was defined with four scan events. The first scan event applied full scan FTMS in profile and normal modes at a resolution of 120,000 for $400 \mathrm{~m} / \mathrm{z}$, scanning a mass window of $500-2000 \mathrm{~m} / \mathrm{z}$. The most abundant ion above an intensity threshold of 500 and $\mathrm{m} / \mathrm{z}$ greater than 700 from the first scan was selected for subsequent fragmentation in a data-dependent manner with an isolation width of 15 and a default charge state of 10. FTMS2 spectra were acquired along a mass window of $300-2000 \mathrm{~m} / \mathrm{z}$ at a resolution of 60,000 at $400 \mathrm{~m} / \mathrm{z}$. Scan events 2 to 4 are described below, as their energy levels varied. The parameters that changed are in bold.

In the "low" energy FTMS2 method, the precursor underwent ETD fragmentation during the second scan event with an activation time of $5 \mathrm{~ms}$ and an activation Q of 0.250; CID fragmentation in the third scan event with a NCE of $35 \mathrm{eV}$, an activation $\mathrm{Q}$ of 0.400 , and an activation time of $100 \mathrm{~ms}$; and HCD fragmentation with a NCE of $19 \mathrm{eV}$ and an activation time of $0.1 \mathrm{~ms}$.

In the "mid" energy FTMS2 method, the precursor underwent ETD fragmentation during the second scan event with an activation time of $10 \mathrm{~ms}$ and an activation $\mathrm{Q}$ of 0.250; CID fragmentation in the third scan event with a NCE of $42 \mathrm{eV}$, an activation $\mathrm{Q}$ of 0.400 , and an activation time of $100 \mathrm{~ms}$; and HCD fragmentation with a NCE of $23 \mathrm{eV}$ and an activation time of $0.1 \mathrm{~ms}$.

In the "high" energy FTMS2 method, the precursor underwent ETD fragmentation during the second scan event with an activation time of $15 \mathrm{~ms}$ and an activation $\mathrm{Q}$ of 0.250; CID fragmentation in the third scan event with a NCE of $50 \mathrm{eV}$, an activation $\mathrm{Q}$ of 0.400 , and an activation time of $100 \mathrm{~ms}$; and HCD fragmentation with a NCE of $27 \mathrm{eV}$ and an activation time of $0.1 \mathrm{~ms}$. 


\subsection{Data Files Analysis}

\subsubsection{Analysis of Infusion MS/MS Spectra}

Manual Annotations of Standards

Given the MW of myoglobin, $\beta$-lactoglobulin, $\alpha$-S1-casein, and the 240,000 resolution of the instrument, the spectra of these proteins were isotopically resolved. Bovine serum albumin is too large for isotopic resolution, therefore only average mass was obtained. Isotopically resolved RAW files were opened using the Qual Browser module of Xcalibur softawe version 3.1 (Thermo Scientific) and deconvoluted using Xtract algorithm (Thermo Scientific) with the following parameters: $\mathrm{M}$ masses mode, 240,000 resolution at $400 \mathrm{~m} / \mathrm{z} 3 \mathrm{~S} / \mathrm{N}$ threshold, 44 fit factor, $25 \%$ remainder, averaging method and 40 max charges. In the deconvoluted spectra, the second scan corresponding to the monoisotopic zero-charge (deisotoped) mass spectrum was selected for export as explained in [31].

Deconvoluted exact masses were then exported to Excel 2016 (Microsoft, Redmond, WA, USA) to generate pivot tables and charts. VBA macros were used to compile lists of masses corresponding to different MS/MS modes and parameters and parent ions from the same protein. The deconvoluted, deisotoped masses were copied and pasted into ProSight Lite version 1.4 (Northwestern University, Evanston, IL, USA) with the following parameters: S-carboxamidomethyl-L-cysteine as a fixed modification, monoisotopic precursor mass type, and fragmentation tolerance of $50 \mathrm{ppm}$. The AA sequence varied according to the standards analysed; where needed, the initial methionine residue (myoglobin), the signal peptide ( $\beta-\mathrm{LG}, \alpha-\mathrm{S} 1-\mathrm{CN}, \mathrm{BSA})$, and the pro-peptide (BSA) were removed. Dependent on the acquisition strategy, the fragmentation type selected was either SID, HCD, CID, or ETD. When multiple MS/MS spectra were used including ETD data, the BY and the CZ fragmentation method was selected.

\section{Automatic Annotations of Standards}

Raw MS/MS files were imported into Proteome Discoverer version 2.2 (Thermo Fisher Scientific) through the Spectrum Files node, and the following parameters were used in the Spectrum Selector node: use MS1 precursor with isotope pattern, lowest charge state of 2, precursor mass ranging from $500-50,000 \mathrm{Da}$, minimum peak count of 1, MS orders 1 and 2, collision energy ranging from 0-1000, full scan type. The selected spectra were then deconvoluted through the Xtract node with the following parameters: S/N threshold of 3, 300-2000 $\mathrm{m} / \mathrm{z}$ window, charge from 1-30 (maximum value), resolution of 60,000 , and monoisotopic mass. When not specified, default parameters were used. Deconvoluted spectra $\left(\mathrm{MH}^{+}\right)$were then exported as a single MGF file.

The MGF file was searched in Mascot version 2.6.1 (MatrixScience, Boston, MA, USA) with top-down searches licence. An MS/MS ion search was performed with the NoCleave enzyme, carbamidomethyl (C) as fixed modification and oxidation (M), acetyl (protein N-term), and phospho (ST) as variable modifications, with monoisotopic masses, $1 \%$ precursor mass tolerance, $\pm 50 \mathrm{ppm}$ or \pm 2 Da fragment mass tolerance, precursor charge of $+1,9$ maximum missed cleavages, and instrument type that accounted for CID, HCD, and ETD fragments (i.e., b-, c-, y-, and z-type ions) of up to $110 \mathrm{kDa}$. The no-enzyme option ("none") was also tested but yielded fewer hits and therefore is not presented here. The first database searched was a FASTA file containing the AA sequences of all the known variants of cow's milk's most abundant proteins (all caseins, alpha-lactalbumin, beta-lactoglobulin, and BSA) along with horse's myoglobin (59 sequences in total, [28]). The decoy option was selected. The second database searched was SwissProt (all 559,228 entries, version 5, last updated on 8 March 2019) using all the entries or just the "other mammalia" taxonomy. 


\subsubsection{Analysis of LC-MS and LC-MS/MS Data from Cannabis Samples}

Statistical Analyses of Cannabis Samples

The RAW files were loaded and processed in the Refiner modules of Genedata Expressionist ${ }^{\circledR}$ version 12.0.6 using the following steps and parameters: profile data cutoff of 10,000 , $R$ window of 3-99 min, $\mathrm{m} / \mathrm{z}$ window of 500-1800 Da, removal of RT structures $<4$ scans, removal of $\mathrm{m} / \mathrm{z}$ structures $<5$ points, smoothing of chromatogram using a 5 scans window and moving average estimator, spectrum smoothing using a 3 points $\mathrm{m} / \mathrm{z}$ window, a chromatogram peak detection using a summation window of 15 scans, a minimum peak size of $1 \mathrm{~min}$, a maximum merge distance of $10 \mathrm{ppm}$, and a curvature-based algorithm with local maximum and FWHM boundary determination, isotope clustering using a peptide isotope shaping method with charges ranging from 2-25 (maximum value) and monoisotopic masses, singleton filtering, and charges and adduct grouping using a 50 ppm mass tolerance, positive charges, and dynamic adduct list containing protons, $\mathrm{H}_{2} \mathrm{O}, \mathrm{K}-\mathrm{H}$, and Na-H. The protein groups were used for statistical analyses.

Spectral deconvolution from 3-70 kDa was performed using manual deprecated mode and harmonic suppression deconvolution method with a 0.04 Da step as well as curvature-based peak detection, intensity-weighed computation, and inflection points to determine boundaries. This step generated LC-MS maps of protein deisotoped masses.

Group volumes were exported to the Analyst module of Genedata Expressionist to perform statistical analyses. Parameters for principal component analysis (PCA) were analysis of rows, covariance matrix, $70 \%$ valid values, and row mean imputation. Parameters for hierarchical clustering analysis (HCA) were clustering of columns, shown as tree, positive correlation distances, Ward linkage, and $70 \%$ valid values.

Identifications of Cannabis Protein by Mascot

The RAW files were processed in Proteome Discoverer version 2.2 (Thermo Fisher Scientific) as detailed above for the known protein standards to create a single MGF file containing 11,250 MS/MS peak lists.

The MGF file was searched in Mascot version 2.6.1 (MatrixScience) with top-down searches licence. An MS/MS ion search was performed with the NoCleave enzyme, carbamidomethyl (C) as fixed modification and oxidation (M), acetylation (protein $\mathrm{N}$-term and $\mathrm{K}$ ), methylation (K), and phosphorylation (ST) as variable modifications, with monoisotopic masses, $\pm 1 \%$ precursor mass tolerance, $\pm 50 \mathrm{ppm}$ or \pm 2 Da fragment mass tolerance, precursor charge of $1+, 9$ maximum missed cleavages, and instrument type that accounted for CID, HCD, and ETD fragments (i.e., b-, c-, y-, and z-type ions) of up to $110 \mathrm{kDa}$. Several databases were searched. The first database searched was the smallest and the most specific and contained all UniprotKB AA sequences from C. sativa and close relatives previously used for our BUP (bottom up) study [1], which was updated on 21 August 2019, thus amounting to 663 entries in total (i.e., 73 sequences added in 6 months). The second database searched was the least specific SwissProt viridiplantae (39,800 sequences; version 5; last updated 8 March 2019). The third database searched was the largest and was compiled on 21 August 2019 using all the C. sativa protein sequences (59,525 in total) from three sources: (1) UniprotKB (663 accessions, https://www.uniprot.org/uniprot/?query=taxonomy:3744\%20cannabis\%20sativa), (2) NCBI (1451 accessions, https://www.ncbi.nlm.nih.gov/protein/?term=(cannabis+sativa)+AND+ $\% 22$ Cannabis+sativa\%22\%5Bporgn\%3A_txid3483\%5D), and (3) the Medicinal Plant Genomic Resource (MPGR) (57,411 accessions, http://medicinalplantgenomics.msu.edu/pub/data/MPGR/Cannabis_ sativa/). The decoy option was selected. The error tolerant option was tested as well but was not pursued, as search times proved much longer and number of hits diminished. For the MPGR hits that remained unannotated, the AA sequence was retrieved and blasted in UniprotKB (https://www.uniprot.org/blast/). 


\section{Results and Discussion}

\subsection{TDS of Infused Protein Standards}

The known protein standards tested were myoglobin (Myo), $\beta$-lactoglobulin ( $\beta$-LG), $\alpha$-S1-casein $(\alpha-S 1-C N)$, and bovine serum albumin (BSA), which vary not only in their AA sequence and their MW but also in the number of disulfide bridges and PTMs they present. Only mature AA sequences, i.e., not including initial methionine residues and signal peptides, are used for sequencing annotations. Myoglobin (P68083., 153 AAs) can carry a phosphoserine on its third residue, $\beta$-lactoglobulin (P02754, 162 AAs) has two disulfide bonds, $\alpha$-S1-casein (P02662, 199 AAs) is constitutively phosphorylated with up to nine phosphoserines, and BSA (P02769, 583 AAs) contains 35 disulfide bonds as well as various PTMs, most of which are phosphorylations. Oxidation of methionine residues of protein standards was encountered, possibly resulting from vortexing during the sample preparation. Precursors of oxidized proteoforms were purposefully disregarded in the manual annotation step; however, they were included as a dynamic modification for the Mascot search.

Tandem MS data from infused known protein standards fragmented using SID, ETD, CID, and HCD were processed either manually in order to include SID data, which are not considered as genuine MS/MS data, or automatically on bona fide MS/MS data only to test whether an automated workflow would successfully reproduce manual searches and therefore could be applied to unknown proteins from cannabis samples (Figure 1). For this labour-intensive and time-consuming manual curation process, only MS/MS data that corresponded to a match against a major isoform were used. Those corresponding to modified proteoforms such as oxidised myoglobin were ignored.

3.1.1. Different Fragmentation Modes Produce Different Spectral Patterns in a Precursor-Dependent Manner

Myoglobin was used to illustrate that the precursor charge state influences the MS/MS spectral pattern, regardless of the fragmentation type; this observation holds true for each standard studied here. Figure 2 displays spectra from myoglobin acquired following SID, ETD, CID, and HCD where increased energy was applied. No fragmentation was observed at SID $15 \mathrm{~V}$. Fragmentation of the most abundant ions of lower $\mathrm{m} / \mathrm{z}$ started to occur at SID $45 \mathrm{~V}$ (not shown), was evident at SID $60 \mathrm{~V}$, and completed at SID $100 \mathrm{~V}$ (Figure 2A).

Whilst MS/MS spectra of the most abundant multiply-charged ions were obtained as attested in Table 1, only two charge states, $942.68 \mathrm{~m} / \mathrm{z}(\mathrm{z}=+18)$ and $1211.79 \mathrm{~m} / \mathrm{z}(\mathrm{z}=+14)$, are exemplified in Figure 2B,C, respectively. Applying ETD for increasingly longer periods, from 5 to 25 ms, resulted in greater protein fragmentations. As ETD fragmentation improved, the fragments' mass range extended from intermediate to high $\mathrm{m} / \mathrm{z}$ values (Figure 2B). Less fragmentation was observed when ETD was applied for $5 \mathrm{~ms}$ (356 and 143 deisotoped fragments for $942.68 \mathrm{~m} / \mathrm{z}$ and $1211.79 \mathrm{~m} / \mathrm{z}$, respectively) than when ETD was sustained for longer activation times (Table 1). 


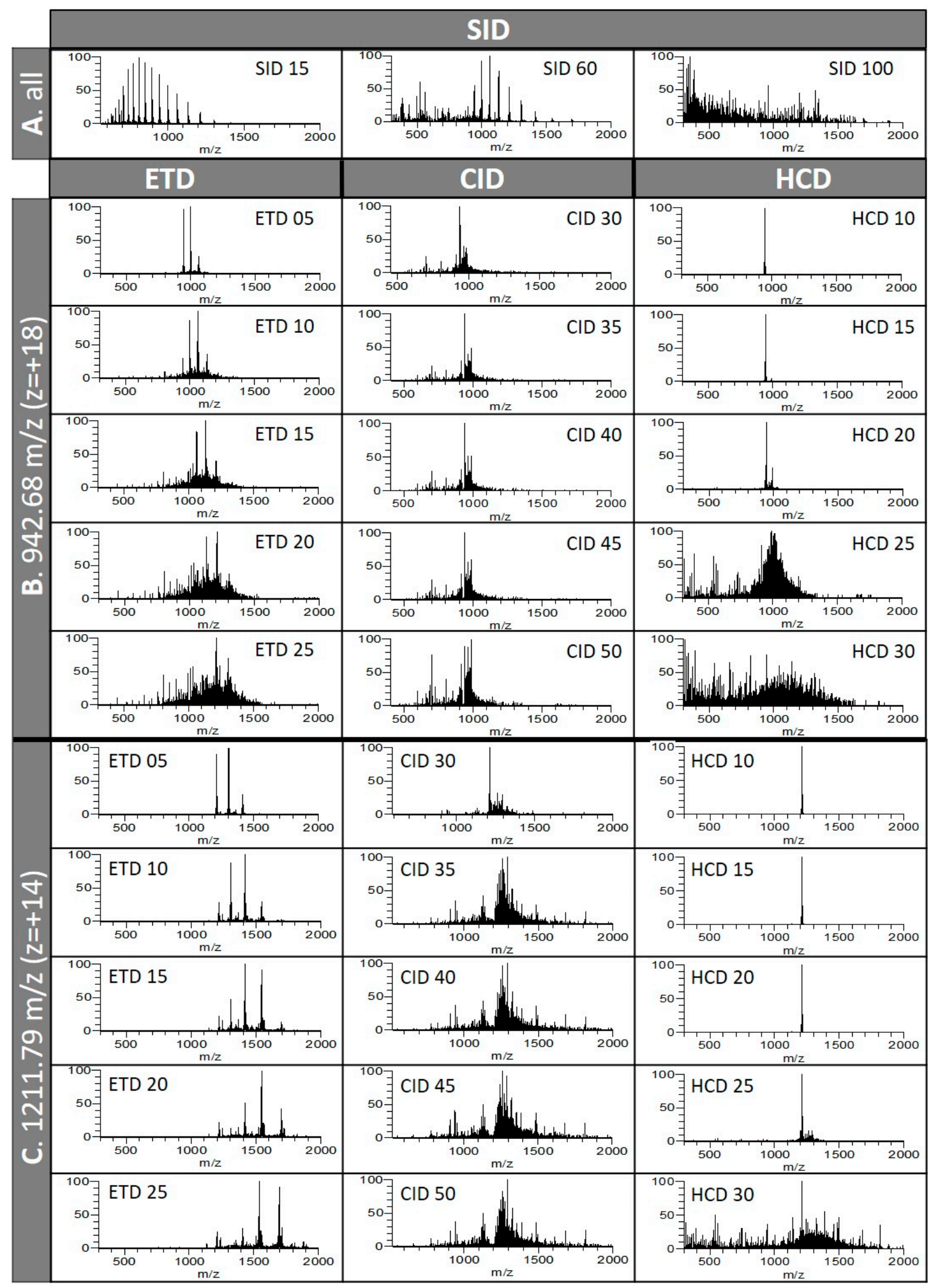

Figure 2. Fourier-transform Orbitrap (FTMS) and FTMS/MS spectra from infused myoglobin. (A) Fragmentation of all ions by source-induced dissociation (SID); (B) fragmentation of ion $942.68 \mathrm{~m} / \mathrm{z}$ $(\mathrm{z}=+18)$ by electron transfer dissociation (ETD), collision-induced dissociation (CID), and higher-energy collisional dissociation (HCD); (C) fragmentation of ion $1211.79 \mathrm{~m} / z(\mathrm{z}=+14)$ by ETD, CID, and HCD. 
Table 1. Number of spectral MS/MS fragments for each protein standard, each MS/MS mode, and energy parameters. The higher the number of fragments is, the darker the colour is.

\begin{tabular}{|c|c|c|c|c|c|c|c|c|c|c|c|c|c|c|c|c|c|c|c|c|c|c|c|c|}
\hline & & & $\begin{array}{l}\text { MS/MS } \\
\text { Mode }\end{array}$ & SID & SID & SID & CID & CID & CID & CID & CID & ETD & ETD & ETD & ETD & ETD & HCD & HCD & HCD & HCD & HCD & $\min$ & $\max$ & mean \\
\hline & & & NCE & 15 & 60 & 100 & 30 & 35 & 40 & 45 & 50 & 5 & 10 & 15 & 20 & 25 & 10 & 15 & 20 & 25 & 30 & & & \\
\hline Protein & $\mathrm{m} / \mathrm{z}$ & $\mathrm{z}$ & RI (\%) ${ }^{1}$ & & & & & & & & & & & & & & & & & & & & & \\
\hline Myoglobin & all & n.a. & n.a. & 171 & 725 & 656 & & & & & & & & & & & & & & & & 171 & 656 & 517 \\
\hline Myoglobin & 848.51 & 20 & 100 & & & & 210 & 255 & 223 & 226 & 233 & 220 & 66 & 120 & 135 & 89 & 102 & 146 & 250 & 253 & 303 & 66 & 303 & 189 \\
\hline Myoglobin & 893.22 & 19 & 98 & & & & 174 & 180 & 176 & 219 & 227 & 229 & 172 & 190 & 457 & 431 & 71 & 148 & 244 & 301 & 260 & 71 & 457 & 232 \\
\hline Myoglobin & 942.68 & 18 & 96 & & & & 194 & 233 & 243 & 227 & 209 & 356 & 470 & 504 & 516 & 468 & 116 & 175 & 280 & 511 & 376 & 116 & 516 & 325 \\
\hline Myoglobin & 1211.79 & 14 & 38 & & & & 241 & 369 & 389 & 385 & 402 & 143 & 392 & 455 & 411 & 365 & 60 & 105 & 252 & 529 & 462 & 60 & 529 & 331 \\
\hline Myoglobin & 1304.93 & 13 & 24 & & & & 180 & 389 & 411 & 383 & 368 & 79 & 282 & 273 & 309 & 263 & 42 & 118 & 262 & 499 & 572 & 42 & 572 & 295 \\
\hline Myoglobin & mean & & & 171 & 725 & 656 & 200 & 285 & 288 & 288 & 288 & 205 & 276 & 308 & 366 & 323 & 78 & 138 & 258 & 419 & 395 & & & 274 \\
\hline b-LG A & all & n.a. & n.a. & 543 & 2160 & 3882 & & & & & & & & & & & & & & & & 543 & 3882 & 2195 \\
\hline b-LG A & 972.19 & 19 & 46 & & & & 336 & 392 & 333 & 358 & 343 & 379 & 375 & 325 & 412 & 242 & 155 & 395 & 504 & 310 & 298 & 155 & 504 & 344 \\
\hline b-LG A & 1026.15 & 18 & 74 & & & & 344 & 412 & 397 & 439 & 387 & 220 & 271 & 137 & 170 & 102 & 230 & 469 & 588 & 449 & 350 & 102 & 588 & 331 \\
\hline b-LG A & 1091.40 & 17 & 80 & & & & 397 & 507 & 474 & 511 & 440 & & & & & & 252 & 608 & 815 & 634 & 443 & 252 & 815 & 508 \\
\hline b-LG A & 1232.84 & 15 & 100 & & & & 481 & 529 & 571 & 531 & 544 & 160 & 456 & 433 & 431 & 443 & 119 & 517 & 664 & 737 & 419 & 119 & 737 & 469 \\
\hline b-LG A & mean & & & 543 & 2160 & 3882 & 390 & 460 & 444 & 460 & 429 & 253 & 367 & 298 & 338 & 262 & 189 & 497 & 643 & 533 & 378 & & & 413 \\
\hline a-S1-CN & all & n.a. & n.a. & 414 & 728 & 891 & & & & & & & & & & & & & & & & 414 & 891 & 678 \\
\hline a-S1-CN & 1139.60 & 21 & 94 & & & & 159 & 455 & 401 & 455 & 435 & & & & & & 112 & 660 & 660 & 431 & 289 & 112 & 660 & 406 \\
\hline a-S1-CN & 1193.38 & 20 & 100 & & & & 166 & 460 & 466 & 389 & 375 & 111 & 424 & 352 & 292 & 193 & 120 & 702 & 651 & 519 & 301 & 111 & 702 & 368 \\
\hline a-S1-CN & 1319.30 & 18 & 70 & & & & & & & & & 97 & 302 & 224 & 209 & 145 & 51 & 721 & 586 & 544 & 256 & 51 & 721 & 314 \\
\hline a-S1-CN & 1397.14 & 17 & 52 & & & & 51 & 247 & 259 & 254 & 259 & & & & & & & & & & & 51 & 259 & 214 \\
\hline a-S1-CN & 1480.59 & 16 & 36 & & & & & & & & & & & & & & 46 & 472 & 464 & 459 & 251 & 46 & 472 & 338 \\
\hline a-S1-CN & mean & & & 414 & 728 & 891 & 125 & 387 & 375 & 366 & 356 & 104 & 363 & 288 & 251 & 169 & 82 & 639 & 590 & 488 & 274 & & & 324 \\
\hline BSA & all & n.a. & n.a. & & 84 & 436 & & & & & & & & & & & & & & & & 84 & 436 & 260 \\
\hline BSA & 953.93 & 72 & 72 & & & & & & & & & 0 & 161 & 58 & 124 & 58 & 0 & 232 & 238 & 113 & 85 & 0 & 238 & 107 \\
\hline BSA & 994.98 & 69 & 76 & & & & 0 & 182 & 150 & 153 & 157 & & & & & & 0 & 196 & 227 & 121 & 87 & 0 & 227 & 127 \\
\hline BSA & 1061.50 & 65 & 68 & & & & 0 & 203 & 177 & 196 & 223 & 0 & 359 & 409 & 352 & 277 & & & & & & 0 & 409 & 220 \\
\hline BSA & 1188.08 & 59 & 44 & & & & 0 & 109 & 96 & 101 & 125 & & & & & & & & & & & 0 & 125 & 86 \\
\hline BSA & mean & & & & 84 & 436 & 0 & 165 & 141 & 150 & 168 & 0 & 260 & 234 & 238 & 168 & 0 & 214 & 233 & 117 & 86 & & & 145 \\
\hline
\end{tabular}


The maximum number of fragments was obtained with $20 \mathrm{~ms}$ for $942.68 \mathrm{~m} / z$ (516 deisotoped fragments) and $15 \mathrm{~ms}$ from $1211.79 \mathrm{~m} / \mathrm{z}$ (455 deisotoped fragments) (Table 1). In our study, compiling all ETD fragment masses together in Prosight Lite program yielded a myoglobin sequence coverage of $54 \%$. Various proteins comprising myoglobin were analysed previously using an AmaZon ETD mass spectrometer offering an ETD/PRT (proton transfer reaction) option and applying $50 \mathrm{~ms}$ for ETD and $100 \mathrm{~ms}$ for PRT to charge state +19 covered $85 \%$ of myoglobin sequence [32]. Using the newest generation of quadrupole Orbitrap linear ion trap Tribrid hosting a high capacity ETD mode, Riley and colleagues compared the standard ETD mode we used to high capacity ETD (also called EThcD) mode using three known proteins, including myoglobin [33]. High capacity ETD accumulated parent cations in the centre section, allowing larger precursor populations for increased product ion $\mathrm{S} / \mathrm{N}$. Monitoring three charge states of myoglobin $(\mathrm{z}=+21,+18,+15)$, maximums of $49 \%$ and $63 \%$ AA sequence coverages were achieved using standard ETD and EThcD, respectively. The authors show that higher charge states of myoglobin were more amenable to ETD fragmentation and that averaging more transient improved $\mathrm{S} / \mathrm{N}$ and therefore sequencing. In a follow-up study, the same group employed activated ion-electron transfer dissociation (AI-ETD), a method that leverages concurrent infrared photoactivation to enhance electron-driven dissociation, and was able to achieve $65 \%$ sequence coverage for charge state +22 of myoglobin [34]. Another team of researchers employed a custom-built high-field FT-ICR mass spectrometer, which enables high-level interrogation of intact proteins in the most detail to date, with the integration of a front-end ETD (FETD) to top-down sequence various proteins, which included myoglobin [35]. The authors show that increasing the cumulative ion (AGC) target led to increased sequence coverage, albeit in a protein size-dependent fashion; the larger the protein is, the greater the AGC target needs to be. They were also able to achieve $65 \%$ AA sequence coverage of myoglobin with a $3.0 \times 10^{6}$ AGC target. Aware of this phenomenon, in our study, we chose not to test different AGC target values and rather employed an intermediate value of $1.0 \times 10^{6}$ that suited small to mid-size proteins.

Increasing the energy of CID mode from 35 to $50 \mathrm{eV}$ had less impact on fragmentation, as can be visually assessed in Figure 2B,C and in Table 1, with more constant numbers of fragments generated, albeit still increasing with the energy levels applied. As CID fragmentation intensified, more ions of low $\mathrm{m} / \mathrm{z}$ appeared (Figure 2B). The fewest numbers of fragments were obtained at CID $35 \mathrm{eV}$ (194 and 241 deisotoped fragments for $942.68 \mathrm{~m} / \mathrm{z}$ and $1211.79 \mathrm{~m} / \mathrm{z}$, respectively), and maximum numbers were reached at CID $50 \mathrm{eV}$ with 209 and 402 fragments for $942.68 \mathrm{~m} / \mathrm{z}$ and $1211.79 \mathrm{~m} / \mathrm{z}$, respectively (Table 1). In our study, compiling all CID fragment masses together in Prosight Lite program yielded a myoglobin sequence coverage of $44 \%$. Similar to ETD, fragmentation resulting from HCD mode was enhanced as more energy was applied, from 10 to $30 \mathrm{eV}$. This is clearly visible on Figure 2B,C, with only a handful of fragments observed at HCD $10-15 \mathrm{eV}$ and fragmentation fully developing at HCD $20 \mathrm{eV}$ and above. As HCD fragmentation improved, the mass range of the ions visibly extended (Figure 2B,C). Only 116 and 60 deisotoped fragments were detected at HCD $10 \mathrm{eV}$ from $942.68 \mathrm{~m} / \mathrm{z}$ and $1211.79 \mathrm{~m} / z$, respectively, with number of fragments peaking at HCD $25 \mathrm{eV}$ to 511 and 529 for 942.68 $\mathrm{m} / \mathrm{z}$ and $1211.79 \mathrm{~m} / \mathrm{z}$, respectively (Table 1). In our study, compiling all HCD fragment masses together in Prosight Lite program yielded a myoglobin sequence coverage of $57 \%$. The fact that the outcome of fragmentation was much less dependent on a particular collisional value for CID than for HCD was also noted by Shliaha and colleagues [25]. Futhermore, they report that, while CID and HCD spectra are very similar, HCD achieves optimal fragmentation at lower energy levels, which we also observed in our study. Riley and colleagues indicate that HCD yields the least sequence coverage for most precursors of myoglobin and other known proteins, with its best performance usually occurring for the lowest charge-state parent ions [34]. While we also observed that lower charge states of myoglobin responded better to HCD dissociation, we report the highest sequence coverage using HCD data, which contradicts the authors' observations.

The present study reveals that different precursors of the same protein (i.e., different charge states) required different energy level for optimum fragmentation, as evidenced in Table 1. It also shows 
that targeting a lower charge state shifted the fragment masses to the right of the mass range towards high $m / z$ values (Figure 2C). Row averages of fragments across all five charge states of myoglobin $(+20,+19,+18,+14,+13)$ listed in Table 1 highlight that a minimum energy level needed to be reached for any meaningful protein dissociation to occur. As far as myglobin is concerned, these values were $60 \mathrm{eV}$ for SID, $25 \mathrm{eV}$ for HCD, $20 \mathrm{~ms}$ for ETD, and 40-50 eV for CID, sorted in decreasing order. Column averages of fragments across all MS/MS modes indicate that some precursors were more amenable to fragmentation than others, with charge states $+18(942.68 \mathrm{~m} / \mathrm{z})$ and $+14(1211.79 \mathrm{~m} / \mathrm{z})$ on average generating most fragments (325 and 331, respectively, Table 1). This suggests that parent ions displaying both high $\mathrm{m} / \mathrm{z}$ (low charge state) and high intensity should be favoured for top-down sequencing experiments. Shliaha and colleagues demonstrate that targeting different charge states provides complementary information; lower charge states respond well to CID and HCD, and higher charge states are more amenable to ETD fragmentation [25]. It is worth mentioning that another type of electron-based fragmentation technology-ECD available on a $Q$ Exactive orbitrap mass spectrometer-produced up to $48 \%$ sequence coverage of myoglobin [36]. Using a hybrid quadrupole FT-ICR mass spectrometer, ECD was demonstrated to outperform CID, particularly on myoglobin [37].

3.1.2. The Central Part of a Protein is Difficult to Fragment, Therefore Recalcitrant to Top-Down Sequencing

Again, we exemplify this observation using myoglobin; however, it was noted on all standards analysed here. All the deconvoluted and the deisotoped masses obtained by applying increasing energy levels of SID, CID, HCD, and ETD were submitted to ProSight Lite and searched against the AA sequence of myoglobin, excluding the initial methionine, which was processed out during the protein maturation step. All the resulting matching $b-, c_{-}, y_{-}$, and z-type ions are reported in Table 2 and plotted according to their position along the mature AA sequence of myoglobin (153 AA). 
Table 2. Number of matching ions in Prosight Lite program (tolerance of $50 \mathrm{ppm}$ ) for each protein standard, each MS/MS mode, and energy parameters. The higher the number of matching ions is, the darker the colour is.

\begin{tabular}{|c|c|c|c|c|c|c|c|c|c|c|c|c|c|c|c|c|c|c|c|c|c|c|c|c|c|c|}
\hline & & & $\begin{array}{l}\text { MS/MS } \\
\text { Mode }\end{array}$ & SID & SID & SID & CID & CID & CID & CID & CID & ETD & ETD & ETD & ETD & ETD & HCD & HCD & HCD & HCD & HCD & $\min$ & $\max$ & mean & No. AAs & $\% \max$ \\
\hline & & & NCE & 15 & 60 & 100 & 30 & 35 & 40 & 45 & 50 & 5 & 10 & 15 & 20 & 25 & 10 & 15 & 20 & 25 & 30 & & & & & \\
\hline Protein & $m / z$ & $\mathbf{z}$ & RI (\%) ${ }^{1}$ & & & & & & & & & & & & & & & & & & & & & & & \\
\hline Myoglobin & all & n.a. & n.a. & 1 & 19 & 20 & & & & & & & & & & & & & & & & 1 & 20 & 13 & 153 & 13 \\
\hline Myoglobin & 848.51 & 20 & 100 & & & & 10 & 12 & 11 & 10 & 19 & 25 & 17 & 28 & 40 & 28 & 2 & 4 & 9 & 17 & 17 & 2 & 40 & 17 & 153 & 26 \\
\hline Myoglobin & 893.22 & 19 & 98 & & & & 4 & 8 & 8 & 9 & 12 & 6 & 24 & 17 & 45 & 48 & 3 & 2 & 11 & 11 & 11 & 2 & 48 & 15 & 153 & 31 \\
\hline Myoglobin & 942.68 & 18 & 96 & & & & 10 & 12 & 14 & 14 & 14 & 17 & 36 & 45 & 57 & 53 & 2 & 5 & 22 & 33 & 22 & 2 & 57 & 24 & 153 & 37 \\
\hline Myoglobin & 1211.79 & 14 & 38 & & & & 27 & 42 & 44 & 39 & 36 & 5 & 24 & 29 & 36 & 26 & 1 & 2 & 12 & 48 & 52 & 1 & 52 & 28 & 153 & 34 \\
\hline Myoglobin & 1304.93 & 13 & 24 & & & & 13 & 41 & 40 & 44 & 44 & 2 & 21 & 20 & 21 & 19 & 1 & 4 & 7 & 55 & 47 & 1 & 55 & 25 & 153 & 36 \\
\hline Myoglobin & mean & & & 1 & 19 & 20 & 13 & 23 & 23 & 23 & 25 & 11 & 24 & 28 & 40 & 35 & 2 & 3 & 12 & 33 & 30 & 2 & 45 & 20 & 153 & 30 \\
\hline b-LG A & all & n.a. & n.a. & 2 & 27 & 66 & & & & & & & & & & & & & & & & 2 & 66 & 32 & 162 & 41 \\
\hline b-LG A & 972.19 & 19 & 46 & & & & 11 & 17 & 20 & 20 & 21 & 8 & 20 & 14 & 20 & 20 & 1 & 14 & 19 & 15 & 21 & 1 & 21 & 16 & 162 & 13 \\
\hline b-LG A & 1026.15 & 18 & 74 & & & & 11 & 18 & 19 & 20 & 17 & 4 & 9 & 9 & 14 & 11 & 6 & 28 & 24 & 22 & 20 & 4 & 28 & 15 & 162 & 17 \\
\hline b-LG A & 1091.40 & 17 & 80 & & & & 11 & 24 & 23 & 26 & 18 & & & & & & 5 & 34 & 29 & 28 & 26 & 5 & 29 & 22 & 162 & 18 \\
\hline b-LG A & 1232.84 & 15 & 100 & & & & 23 & 23 & 21 & 23 & 22 & 4 & 8 & 12 & 13 & 19 & 3 & 17 & 27 & 27 & 21 & 3 & 23 & 18 & 162 & 14 \\
\hline b-LG A & mean & & & 2 & 27 & 66 & 14 & 21 & 21 & 22 & 20 & 5 & 12 & 12 & 16 & 17 & 4 & 23 & 25 & 23 & 22 & 3 & 33 & 21 & 162 & 21 \\
\hline a-S1-CN & all & n.a. & n.a. & 1 & 3 & 7 & & & & & & & & & & & & & & & & 1 & 7 & 4 & 199 & 4 \\
\hline a-S1-CN & 1139.60 & 21 & 94 & & & & 4 & 7 & 8 & 7 & 17 & & & & & & 1 & 24 & 37 & 43 & 37 & 1 & 43 & 19 & 199 & 22 \\
\hline a-S1-CN & 1193.38 & 20 & 100 & & & & 2 & 10 & 9 & 10 & 6 & 3 & 23 & 25 & 24 & 25 & 2 & 32 & 41 & 37 & 36 & 2 & 41 & 19 & 199 & 21 \\
\hline a-S1-CN & 1319.30 & 18 & 70 & & & & & & & & & 0 & 13 & 15 & 19 & 18 & 1 & 30 & 35 & 39 & 38 & 0 & 39 & 23 & 199 & 20 \\
\hline a-S1-CN & 1397.14 & 17 & 52 & & & & 6 & 12 & 12 & 9 & 15 & & & & & & & & & & & 6 & 15 & 11 & 199 & 8 \\
\hline a-S1-CN & 1480.59 & 16 & 36 & & & & & & & & & & & & & & 1 & 28 & 33 & 39 & 38 & 1 & 39 & 28 & 199 & 20 \\
\hline a-S1-CN & mean & & & 1 & 3 & 7 & 4 & 10 & 10 & 9 & 13 & 2 & 18 & 20 & 22 & 22 & 1 & 29 & 37 & 40 & 37 & 2 & 31 & 17 & 199 & 15 \\
\hline BSA & all & n.a. & n.a. & & 1 & 4 & & & & & & & & & & & & & & & & 1 & 4 & 2 & 583 & 1 \\
\hline BSA & 953.93 & 72 & 72 & & & & & & & & & 0 & 6 & 4 & 8 & 7 & 0 & 9 & 13 & 11 & 9 & 0 & 13 & 7 & 583 & 2 \\
\hline BSA & 994.98 & 69 & 76 & & & & 0 & 4 & 5 & 5 & 1 & & & & & & 0 & 3 & 11 & 12 & 11 & 0 & 12 & 5 & 583 & 2 \\
\hline BSA & 1061.50 & 65 & 68 & & & & 0 & 6 & 5 & 5 & 6 & 0 & 4 & 8 & 4 & 8 & & & & & & 0 & 8 & 5 & 583 & 1 \\
\hline BSA & 1188.08 & 59 & 44 & & & & 0 & 4 & 2 & 3 & 7 & & & & & & & & & & & 0 & 7 & 3 & 583 & 1 \\
\hline BSA & mean & & & & 1 & 4 & 0 & 5 & 4 & 4 & 5 & 0 & 5 & 6 & 6 & 8 & 0 & 6 & 12 & 12 & 10 & 0 & 9 & 4 & 583 & 2 \\
\hline
\end{tabular}

${ }^{1}$ RI, relative intensity. 
Because different ions of the same protein underwent different types of fragmentation at varying energy levels, the data are quite redundant, as can be seen in Figure $3 \mathrm{~A}$, with many dots depicted at a particular AA position. Higher energy levels produced the most meaningful data, as attested by the prominence of darker shades.

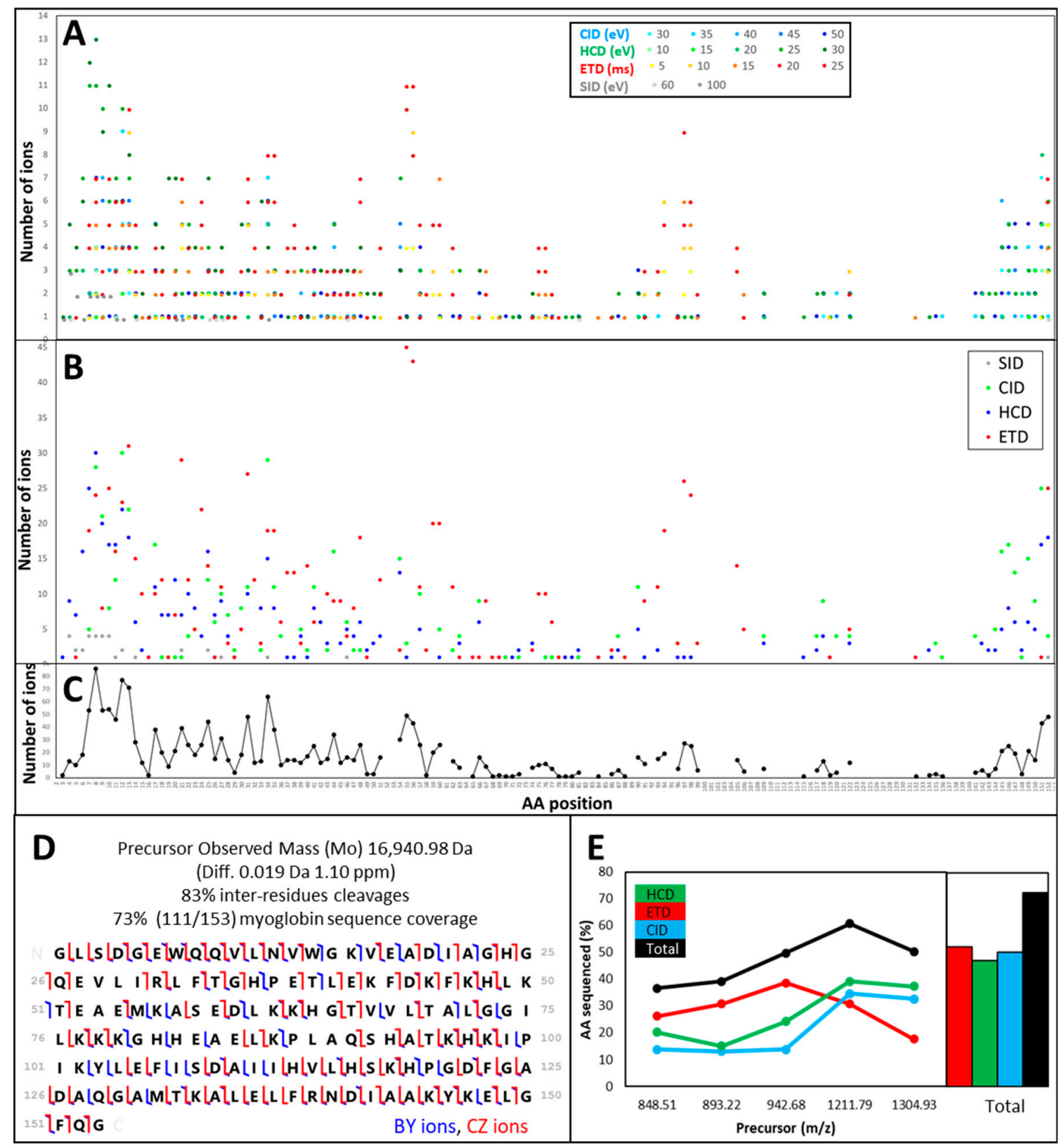

Figure 3. Summary of the number of matching ions in Prosight Lite program achieved for myoglobin. (A) Depicting the number of matched ions for every MS/MS parameter tested summed across all five charge states listed in Table 1; (B) summed by MS/MS mode along myoglobin amino acid (AA) sequence; (C) summed globally across all the data obtained for myoglobin along its AA sequence; (D) global AA sequence coverage when all MS/MS data are considered; (E) percentage of sequence coverage achieved for each of the five myoglobin charge states.

Figure 3B corresponds to the summation of the number of matched ions per MS/MS mode, irrespective of the energy applied. It shows that some parts of the sequence were highly amenable to specific dissociation modes. For instance, ETD was more suited for the $\mathrm{N}$-terminus and the central part of the protein, while CID and HCD helped sequence the C-terminus. CID generated predominantly low 
yield $\mathrm{N}$ - and C-terminal fragments from intact proteins [38]. SID was only effective on the N-terminus of myoglobin. Using an FT-ICR instrument, Cobb and colleagues tested increasingly different SID conditions, also called declustering potentials, from 60 to $240 \mathrm{~V}$ on ubiquitin, myoglobin, and BSA [39]. The authors demonstrate that protein dissociation mechanisms are found to be modulated by both source declustering potential and precursor ion charge state. They also explain the canonical and the non-canonical mechanisms involved and how certain AAs such as Pro and Asn are more amenable to C-terminal fragmentation while other AAs such as Ile, Leu, and Ser tend to cleave at the $\mathrm{N}$-terminus of the protein. Like us, their results show that higher SID potentials yield more fragments [39]. Figure 3C represents a summation of the number of matched ions at each AA position, irrespective of the MS/MS mode or the energy applied. Where fewer dots are displayed, the areas of myoglobin that resisted fragmentation under our conditions became apparent. Myoglobin N-terminus was well covered up to position 99, albeit with some interruptions, whereas the C-terminus was only covered up to the last 10 AAs. The region spanning AAs 100 to 140 of myoglobin was only partially sequenced. Shliaha and colleagues [25] published last year an exhaustive top-down proteomics experiment on infused standards, including myoglobin. The authors indicate that CID and HCD contribute less AA sequence information than ETD, mostly at the protein $\mathrm{N}$ and the $\mathrm{C}$-termini, whereas ETD provides coverage throughout the protein sequence. They conclude that, as far as myoglobin is concerned, ETD outperforms CID and HCD.

The ProSight Lite output is shown in Figure 3D and confirms that both N- and C-termini of myoglobin sequence were well covered, with many AAs identified from $\mathrm{b}-, \mathrm{c}^{-}, \mathrm{y}-$-, and $\mathrm{z}$-types of ions. Some AAs could only be fragmented once, either using ETD or HCD. Therefore, resorting to multiple MS/MS modes was essential to maximise top-down sequencing. Overall, 83\% inter-residues cleavages were annotated, accounting for 73\% (111/153 AAs) sequence coverage of myoglobin (Figure 3D). Figure $3 \mathrm{E}$ summarises top-down sequencing efficiency for myoglobin in our experiment. It varied according to the charge state and the dissociation type. Only when all fragmentation data were put together could the highest sequence coverage be achieved.

\subsubsection{Fragmentation Efficiency Varies from Protein to Protein in a Size-Dependent Fashion}

The commercial standards used in this study and past work $[28,30]$ contained mixtures of protein isoforms. Deconvolution of full scan FTMS1 (Figure 4A) supplied accurate masses for $\beta$-lactoglobulin, $\alpha$-S1-casein, and average masses for BSA with an error $<50 \mathrm{ppm}$, which helped in figuring out which protein isoforms underwent MS/MS analysis and which sequence to use for ProSight Lite annotation. 


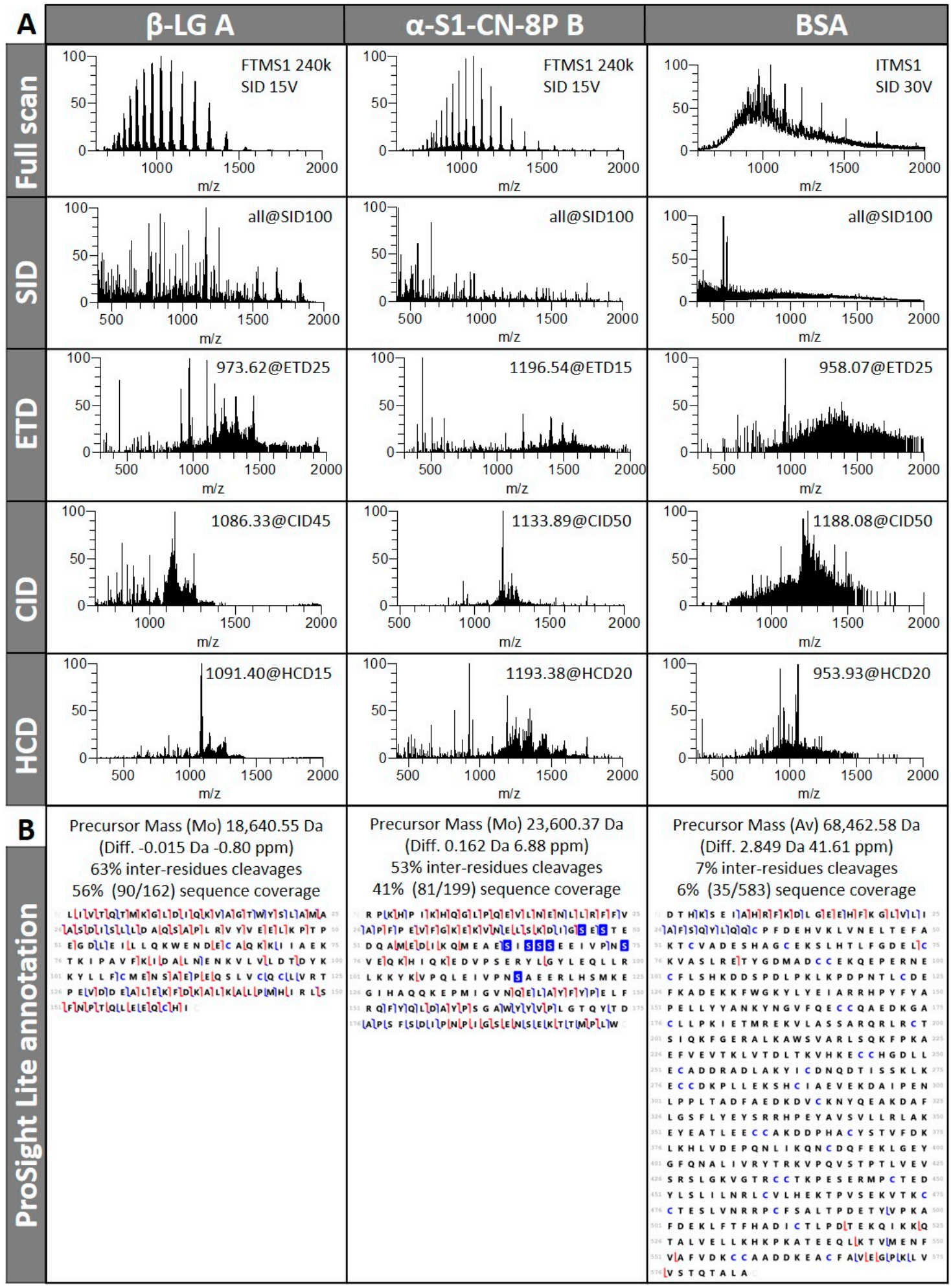

Figure 4. Excerpts of results for $\beta$-lactoglobulin ( $\beta-\mathrm{LG}), \alpha$-S1-casein $(\alpha-\mathrm{S} 1-\mathrm{CN})$, and bovine serum albumin (BSA). (A) Examples of FTMS and FTMS/MS spectra using SID, ETD, CID, and HCD; (B) global AA sequence coverage when all MS/MS data are considered.

Precursors from allelic variant $A$ of $\beta$-lactoglobulin and allelic variant $B$ of $\alpha$-S1-casein with eight phosphorylations were selected for fragmentation. Examples of SID, ETD, CID, and HCD spectra for each protein can be seen in Figure 4A and illustrate how different they are. Theoretical charge state distributions for proteins showed that the absolute number of charges that precursors carried and the 
relative width of the charge state distribution both increased as protein mass was augmented [33]. The authors further mention that, as protein size increased, not only did the measureable signal across more fragment ions spread, but also proportionally larger fragment ions with broader isotope distributions were created, thus impacting $\mathrm{S} / \mathrm{N}$ ratio. In this study, we used a high number of microscans to perform spectral averaging in order to increase $\mathrm{S} / \mathrm{N}$, but the tradeoff was a longer duty cycle and acquisition time, which restricted throughput. In previous works, we employed a Q-ToF instrument that offered a spectral summation option and maximized S/N so much that very little background noise was left without overly prolonging the duty cycle [27-29]. Another advantage of the Q-ToF system is that it tolerated more complex samples without the need for SPE clean-up, which not only minimised the number of steps during sample preparation but also avoided protein loss. Because we wanted to explore different fragmentation modes, we turned to the LTQ-orbitrap mass spectrometer.

The number of deconvoluted deisotoped fragments of all protein standards is listed in Table 1. As previously observed for myoglobin, fragmentation efficiency assessed on the number of fragments generated depended on the charge state of the precursor, the MS/MS mode, and the energy applied, albeit in a protein-specific fashion. For instance, abundant parents of lower charge states yielded numerous fragments in the cases of $\beta$-lactoglobulin $(z=+17,508$ fragments on average) and BSA ( $z=$ $+68,220$ fragments on average), whereas abundant precursor of high charge state yielded numerous fragments in the case of $\alpha$-S1-casein $(z=+21,406$ fragments on average). If we look at which MS/MS mode and which energy level produced the greatest number of fragments on average across all charge states, we find that the ranking for $\beta$-lactoglobulin was SID $100 \mathrm{~V}>$ HCD $20 \mathrm{eV}>\mathrm{CID} 35-45 \mathrm{eV}>$ ETD $10 \mathrm{~ms}$. The ranking for $\alpha$-S1-casein was SID $100 \mathrm{~V}>\mathrm{HCD} 15 \mathrm{eV}>\mathrm{CID} 35 \mathrm{eV}>\mathrm{ETD} 10 \mathrm{~ms}$. The ranking for BSA was SID $100 \mathrm{~V}>$ ETD $10 \mathrm{~ms}>\mathrm{HCD} 20 \mathrm{eV}>\mathrm{CID} 50 \mathrm{eV}$. In a previous top-down study on bovine milk, which included the protein standards used in this work, we showed that higher CID and SID energy levels produce lower $m / z$ ions [29]. A greater AA sequence coverage was achieved for $\beta$-lactoglobulin and $\alpha$-S1-casein in that study; retrospectively, an overestimation as the data processing method employed then did not include a decoy validation step and therefore could not eliminate false positives. Using an LTQ-orbitrap instrument and CID fragmentation in the ITMS, a 17\% (27/162) AA sequence coverage of $\beta$-lactoglobulin was attained [40]. Employing CID and post ion/ion reaction (i.e., in-source decay or ISD, which operates similarly to SID) options offered by MALDI ToF-ToF systems, few fragments were obtained from $\beta$-lactoglobulin singly, doubly, and triply-charged precursors, which prevented correct identification of the protein; myoglobin responded better to this type of dissociation and could be identified based on 21 cleavage sites [41]. Suckau and Resemann cleverly exploited MALDI-ToF-ToF capabilities by first producing ISD fragments of intact proteins and subsequently further dissociating them by CID in a pseudo-MS ${ }_{3}$ experiment; they successfully identified BSA using an N-terminus 24-residue sequence tag [42]. More recently, ISD pseudo $\mathrm{MS}_{3}$ and pseudo $\mathrm{MS}_{4}$ experiments were performed using a MALDI-ToF adapted with a quadrupole ion trap (MALDI-QIT-ToF) instrument to analyse a mixture of known proteins; BSA proved recalcitrant to such strategy [43].

A plethora of fragments does not necessarily translate into high AA sequence coverage, as can be seen when Tables 1 and 2, similarly arranged, are compared. For instance, under an SID potential of $100 \mathrm{~V}, \alpha$-S1-casein produced 891 fragments, of which only $7(0.8 \%)$ were an AA sequence match. This phenomenon of "overfragmentation" is alluded to in literature [25] and would result from secondary dissociation of the initial daughter ions when normalized collision energies are enhanced. Whilst noticeable for all MS/MS modes tested here, the best evidence of this applied to SID fragmentation with, at best, only 3\% (26/656 for myoglobin) of the fragments being annotated in ProSight Lite. Its efficacy in top-down sequencing varied greatly among the proteins studied here, accounting for as little as $1 \%$ coverage of BSA sequence, $4 \%$ coverage of $\alpha$-S1-casein sequence, up to $13 \%$ for myoglobin and an impressive $41 \%$ for $\beta$-lactoglobulin (Table 2). Future tests will endeavour at combining SID with genuine MS/MS modes of the Elite LTQ-orbitrap mass spectrometer and developing the processing workflow to computationally analyse the data. 
When true MS/MS data resulting from ETD, CID, and HCD experiments are considered, high numbers of fragments are a requisite for proper top-down sequencing, yet it was not the MS/MS spectra with the maximum number of peaks that yielded the greatest number of matched ions in ProSight Lite (Tables 1 and 2). For instance, in the case of $\beta$-lactoglobulin precursor $1091.4 \mathrm{~m} / \mathrm{z}$ undergoing HCD fragmentation, 815 fragments were obtained with $20 \mathrm{eV}$, which accounted for 29 matched ions, and 608 fragments were obtained with $15 \mathrm{eV}$, which accounted for 34 matched ions. In another example, this time looking at $\alpha$-S1-casein precursor $1139.6 \mathrm{~m} / z$ undergoing CID fragmentations, $35 \mathrm{eV}$ created 455 fragments with only seven being annotated in Prosight Lite, while 435 fragments obtained with $50 \mathrm{eV}$ led to 17 matches. Compiling all fragmentation data obtained for each protein and submitting them to Prosight Lite program gave the maximum sequence coverage achieved in this study: $56 \%$ for $\beta$-lactoglobulin, $41 \%$ for $\alpha$-S1-casein, and 6\% for BSA (Figure 4B). Shen and colleagues also report improved identification success of peptidome and degradome upon using a combination of CID, HCD, and ETD [44]. Maximised protein sequence coverage following multimodal fragmentation was recently confirmed by Shliaha and colleagues in their intricate top-down proteomics study on infused standards ranging from 10-30 $\mathrm{kDa}$ [25].

We conclude from our experiments on known proteins of different MWs that sequence coverage varies according to the protein itself, its size (Supplementary Figure S1) and intrinsic properties, the abundance and the charge state of the precursor ion, the MS/MS mode, and the level of energy applied. Therefore, not many general rules can be surmised apart from the fact that complementary MS/MS data yield greater sequence coverage. A key factor, however, is the signal intensity. What was apparent in our study was that precursors of higher $\mathrm{S} / \mathrm{N}$ generated better fragmentation spectra (not shown). Generally speaking and under our conditions, medium to high energy levels tend to improve sequence annotation. The observations that optimization performed on one protein cannot be extrapolated to other proteins and the highest coverage can only be achieved by optimizing fragmentation for each protein individually were also recently demonstrated [25].

\subsubsection{Automatic Workflow Success Depends on Database Searched and Tolerance Parameters}

The analysis presented above was exclusively performed manually using the ProSight Lite program. It was very labour-intensive and time-consuming; moreover, it can only be conceived for known proteins such as the standards tested in this study. This is not feasible for complex samples such as plant extracts analysed using an untargeted approach. Therefore, we developed an automated workflow using Proteome Discover to export an MGF containing $371 \mathrm{MS} / \mathrm{MS}$ peak lists, which was submitted to the Mascot algorithm. The parameters bearing the greatest impact on the results were tested, namely the database, the type of dynamic modifications, and the fragment tolerance. The search results are summarised in Supplementary Table S1. The Mascot outcome was then compared to our manual curation. The immediate advantage of automation is the speed at which all the data are processed, not accounting for database search times, which can be significant (days if the error-tolerant option is selected in Mascot program). Another advantage is that the search runs in the background, freeing up time to perform other tasks. Finally, automation greatly limits man-made errors.

In the first instance, a homemade database of 59 FASTA sequences [27-29] comprising horse myoglobin, all known allelic variants of bovine caseins, and the most abundant bovine whey proteins ( $\alpha$-lactalbumin, $\beta$-lactoglobulin, bovine serum albumin) was searched on our local Mascot server using a $\pm 50 \mathrm{ppm}$ fragment tolerance. The Mascot output is reported as a list of proteins and proteoforms in Supplementary Tables S2 and S3, respectively, as well as exemplified in Supplementary Figure S2A. Four accessions are listed based on 105 (28\%) MS/MS spectra matched, correctly identifying myoglobin, $\alpha$-S1-casein variant $B$, and $\beta$-lactoglobulin, albeit not the correct allelic variant. Based on accurate mass and accounting for carbamidomethylation sites, variant $A$ of $\beta$-lactoglobulin was expected, and Mascot identified variants $\mathrm{E}$ and $\mathrm{F}$ instead, which differed at five AA positions due to insufficient sequence coverage. Bovine serum albumin was not identified. Myoglobin achieved the highest score (3782), with $97 \mathrm{MS} / \mathrm{MS}$ spectra yielding annotations, $82 \%$ of them being redundant, 
which was expected, as our data were intended to be highly repetitive. Unmodified myoglobin was the most frequently identified (41\%), as it was indeed the most abundant proteoform in the spectra. Oxidised proteoforms were also identified in combination or not with phosphorylated and acetylated proteoforms. Six MS/MS spectra led to the correct identification of $\alpha$-S1-casein B with a score of 123 . Several proteoforms were listed, all of them oxidized and bearing from six to 13 phosphorylations. Mascot scores for $\beta$-lactoglobulin were below the ion score threshold $(<27)$, indicative of low sequence homology. If the fragment tolerance was increased to $\pm 2 \mathrm{Da}, 13$ proteins were identified from 322 (87\%) MS/MS spectra matches (Supplementary Tables S2 and S3). Search times were in the order of minutes.

In the second instance, all the entries of Swissprot database $(559,228$ sequences) were searched with a \pm 50 ppm fragment tolerance. The Mascot search result is reported in Supplementary Table S2 and Supplementary Figure S2B. Not only was the search much longer than with our smaller, more targeted homemade database (lasting three days), but only myoglobin could be identified based on a total of $46(12 \%)$ matched MS/MS spectra (71\% redundancy) and yielding a protein score of 1456 . As observed with the homemade database, the unmodified isoform was the most frequently identified (39\%), while the other proteoforms bore oxidation and/or phosphorylation sites (Supplementary Table S3). Raising the MS/MS tolerance to 2 Da did not increase the list of proteins identified but brought the score to 8764 with 113 (30\%) matches. Limiting Swissprot taxonomy to "other mammalia" brought myoglobin scores to 17,072 with 62 (17\%) matches and 10,298 with 136 (37\%) matches, respectively, applying $\pm 50 \mathrm{ppm}$ and \pm 2 Da fragment tolerance. While this reduced search times to hours, it also identified a protein we did not expect in our known protein samples, namely NADH-ubiquinone oxidoreductase, albeit with a low score (46, Supplementary Tables S2 and S3). As the commercial standards we used were not pure [30], it is quite possible that this protein was genuinely present in the sample. We concluded that increasing the search space by choosing a database with more entries and selecting more dynamic modifications lengthened the time needed to complete the search (Supplementary Table S1) without necessarily yielding more relevant identities (Supplementary Table S2).

We cannot explain why using Swissprot as a database failed to identify all the proteins analysed here, namely $\alpha$-S1-casein, $\beta$-lactoglobulin, and BSA. Most likely, the quality of the MS/MS spectra and the signal intensity levels were major contributing factors. This highlights the fact that, with larger databases, meaningful information is lost, likely during the decoy search step. Therefore, specific databases that target the species of interest are better suited for protein sequencing experiments. Using our homemade targeted database proved successful in identifying all the analysed known proteins but the largest (BSA), which not only was challenging to resolve isotopically with the system used in this study but also suffered from low intensity levels and therefore low $\mathrm{S} / \mathrm{N}$. Mascot search parameters chosen by Drabik and colleagues imputed different mass tolerances, being more strict $( \pm 1.5 \mathrm{Da})$ at the parent level and less stringent at the product level $( \pm 2 \mathrm{Da})$, which yielded greater score and sequence coverage for myoglobin than in our study [32]. Top down (BIG) Mascot was shown to have limitations by [37]. Mascot consistently provided a higher probability of a false match (i.e., more stringent) compared to the ProSight Lite program. Furthermore, individual internal fragments from large proteins were not confidently matched by Mascot due to, on the one hand, the occurrence of multiple matches, and on the other hand, mass shifts due to PTMs. The authors conclude that the stringency level of Mascot was excessive [37]. Mascot and Open Mass Spectrometry Search Algorithm (OMSSA) algorithm were compared for top-down sequencing purposes [45]. OMSSA identified a larger number of spectra than Mascot; OMSAA displayed better sensitivity and specificity than Mascot. Mascot and OMSSA were then compared to MS-Align+, which significantly yielded a greater number of protein identities [46]. Therefore, it would be worthwhile to test other algorithms than Mascot to prospect top-down proteomics data.

Our tests on protein standards only aimed at reproducing what had been achieved by others in the literature $[25,40,44]$ in order to validate our MS/MS methods; we did not set out to unravel novel information on these standards, which would have been off topic. We successfully used the various 
fragmentation modes offered by the LTQ-orbitrap mass spectrometer (SID, CID, HSD, and ETD) to top-down sequence known proteins of various sizes. The second part of the study aimed at applying these MS/MS methods to unknown proteins from complex plant samples.

\subsection{TDS of Cannabis Proteins}

Satisfied with our tests on known protein standards, we then analysed protein extracts from cannabis mature buds. Extracts were concentrated by evaporation to maximise signal intensity. The chromatographic separation of intact denatured proteins was fine-tuned (not shown) from 15 to $40 \%$ of mobile phase B for $87 \mathrm{~min}$. We decided to not pursue the SID declusturing method and instead only applied ETD, CID, and HCD in succession with three levels of energy, called "low" (ETD $5 \mathrm{ms,}$ CID 35 eV, HCD 19 eV), "mid" (ETD 10 ms, CID 42 eV, HCD 23 eV), and "high" (ETD 15 ms, CID 50 eV, $\mathrm{HCD} 27 \mathrm{eV})$.

\subsubsection{LC-MS and LC-MS/MS Patterns of Cannabis Protein Extracts are Very Reproducible}

The three cannabis extracts (buds 1 to 3 ) were run using LC-MS in duplicate and using LC-MS/MS in triplicate with high reproducibility (Figure 5).

Total ion chromatograms (TIC) were very similar across technical replicates as well as among biological replicates 2 and 3 (Figure 5A); sample bud 1 differed slightly, mostly due to lower signal intensities during the first half of the LC run. LC-MS patterns were very similar, generally differing in peak intensities across biological replicates (Figure 5B), as the number of protein groups was consistent with small standard deviation (SD) values ( $470 \pm 17$ groups) (Table 3A).

Maps of deconvoluted masses were also highly comparable, with a greater majority of proteins (93\%) being smaller than 20 kD (Supplementary Figure S3 and Figure 5C); a zoom-in confirmed the lesser intensity of bud 1 pattern (Figure 5D). If we compare these LC-MS patterns with those we previously published ([1]), the most obvious difference is the disappearance of the late eluting compounds of low $\mathrm{m} / \mathrm{z}$ values. These abundant singly-charged compounds were eliminated during the clean-up SPE we added in the present study. Other improvements included increasing the chromatographic separation from 60 to $120 \mathrm{~min}$ and using UPLC column packed with a C4 rather than a C8 stationary phase. This resulted in better utilization of the 500-2000 $\mathrm{m} / \mathrm{z}$ range (503-1799 $\mathrm{m} / \mathrm{z}$ ), enhanced dynamic range (from $10^{4}$ to $10^{8}$, i.e., four orders of magnitude), increased numbers of multiply-charged ions, and overall superior and more reproducible LC-MS profiles.

The triplicated LC-MS/MS patterns were also very similar, as exemplified in bud 1 in Figure 5E. Table 3B lists the number of MS/MS spectra per sample (1160 to $1220 \mathrm{MS} / \mathrm{MS}$ spectra on average) and method (1178 to $1189 \mathrm{MS} / \mathrm{MS}$ spectra on average); SD values were very small and comparable across samples ( \pm 8 to 11 ) and methods ( \pm 22 to 31 ), indicative of high repeatability. The reproducibility of the LC-MS and the LC-MS/MS analyses was statistically assessed (Supplementary Figure S4). PCA clearly separated LC-MS data from LC-MS/MS data along Eigenrow 1 and bud 1 sample from the other two biological samples along Eigenrow 2. Technical replicates were clustered together. This was confirmed by HCA.

Table 3. Statistics on cannabis proteins analysed by LC-MS and LC-MS/MS. (A) Number of protein groups obtained from Genedata Refiner analysis of the LC_MS data across the three biological replicates (buds 1 to 3) and two technical replicates (replicate 1 and 2); (B) number of MS/MS spectra collected for each biological replicate (bud 1 to 3 ) across each "low, "mid", and "high" MS/MS method.

\begin{tabular}{|c|c|c|c|c|c|c|c|c|c|c|c|}
\hline (A) & & & & & & (B) & & & & & \\
\hline Tech. Rep. & bud 1 & bud 2 & bud 3 & Mean & SD & Method & bud 1 & bud 2 & bud 3 & Mean & SD \\
\hline Replicate 1 & 442 & 483 & 483 & 469 & 19 & "Low" & 1157 & 1169 & 1208 & 1178 & 22 \\
\hline Replicate 2 & 474 & 486 & 453 & 471 & 14 & "Mid" & 1173 & 1193 & 1226 & 1197 & 22 \\
\hline mean & 458 & 485 & 468 & 470 & 17 & “High” & 1149 & 1192 & 1225 & 1189 & 31 \\
\hline \multirow[t]{2}{*}{ SD } & 16 & 2 & 15 & & & mean & 1160 & 1185 & 1220 & & \\
\hline & & & & & & SD & 10 & 11 & 8 & & \\
\hline
\end{tabular}



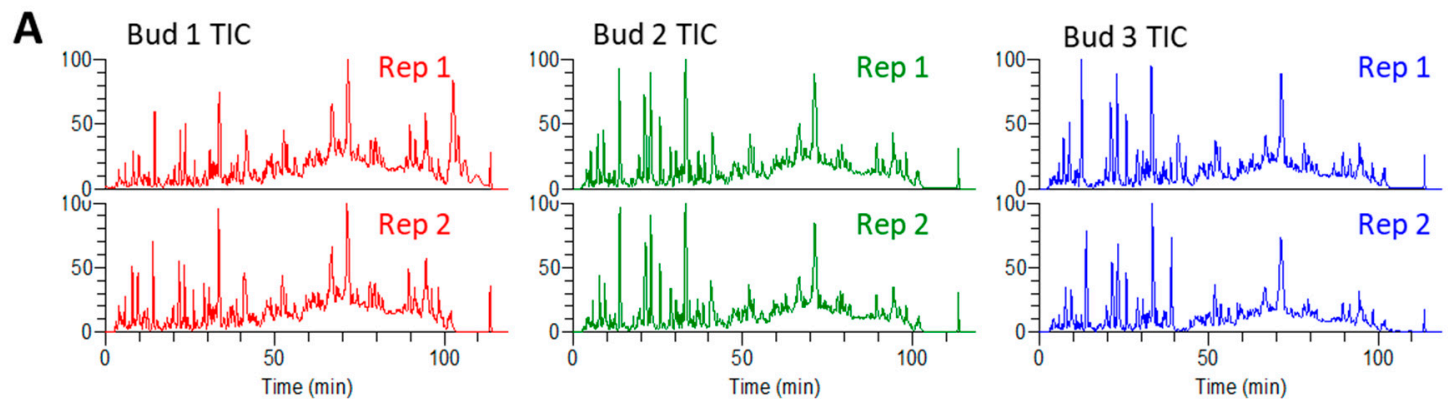

B
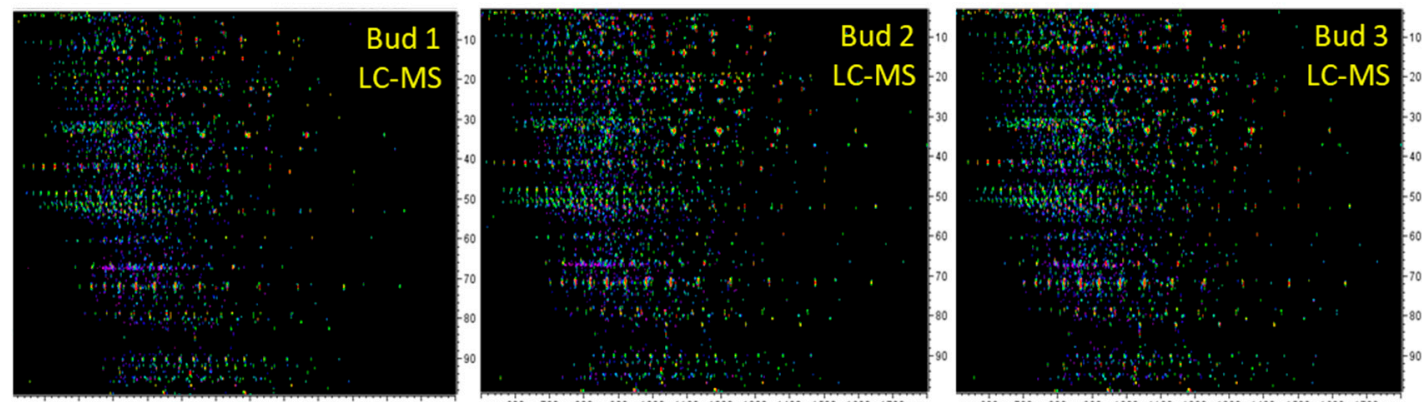

C
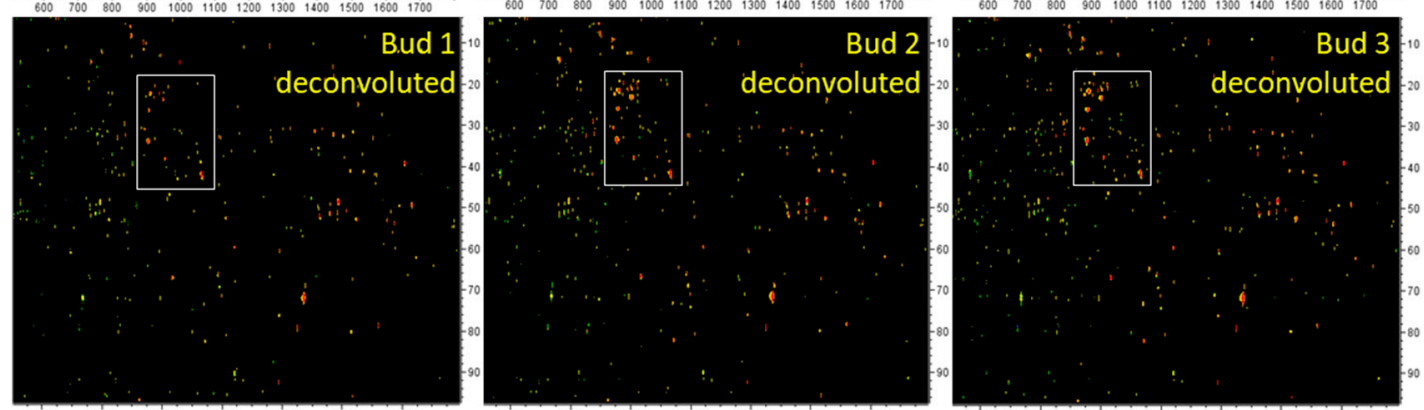

D
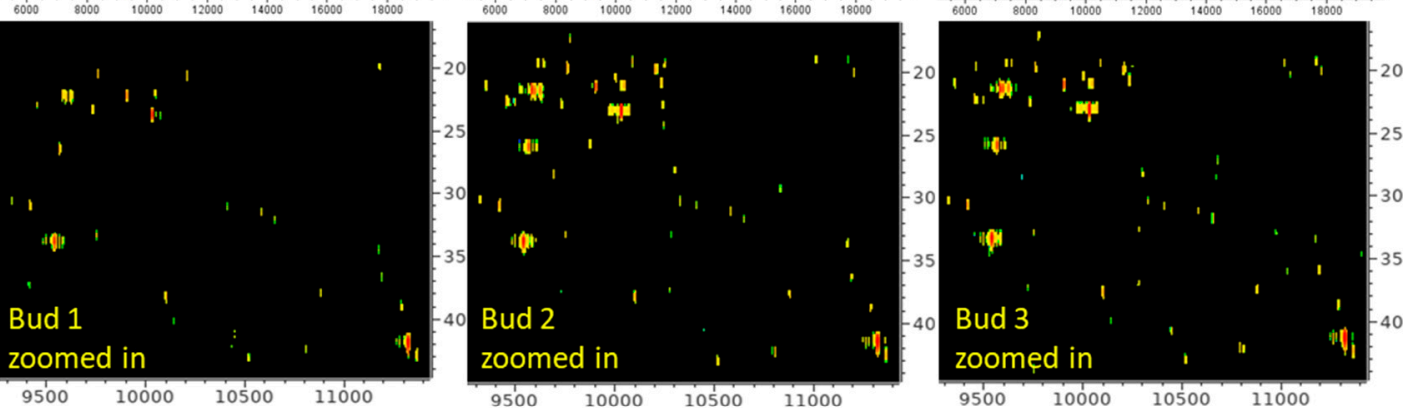

E
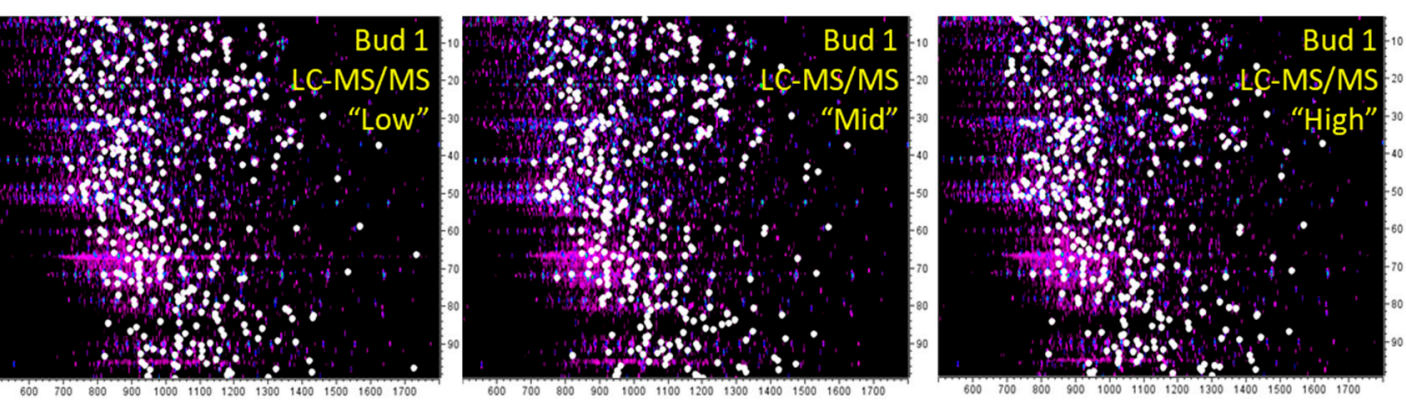

Figure 5. Profiles of medicinal cannabis protein samples. (A) Total ion chromatograms (TIC) for each biological replicate (buds 1 to 3 ) and technical duplicate (reps 1 and 2). Elution times (min) are along the $\mathrm{x}$-axis, and the signal intensity is along the y-axis; (B) LC-MS pattern of each biological replicate (buds 1 to 3) (rep 1). Mass range (500-2000 $\mathrm{m} / \mathrm{z}$ ) is along the x-axis, and elution times (min) are along the y-axis; (C) Deconvoluted LC-MS map of each biological replicate (buds 1 to 3) (rep 1) along 3-30 kDa on the x-axis; (D) zoom-in the area boxed in (C) along 15-45 min and 9-11.5 kDa corresponding to abundant proteins; (E) triplicated LC-MS/MS patterns from biological replicate bud 1; dots represent MS/MS events. 


\subsubsection{Proteins from Cannabis Buds are Small}

The most abundant multiply-charged precursors targeted for MS/MS fragmentation are listed in Table 4, which also highlights some of their features.

Table 4. Statistics on parent ions from cannabis proteins analysed by LC-MS/MS.

\begin{tabular}{ccccccc}
\hline $\begin{array}{c}\text { Charge } \\
\text { State }\end{array}$ & $\begin{array}{c}\text { No. of } \\
\text { Precursors }\end{array}$ & Min. $m / z$ & Max. $m / z$ & $\begin{array}{c}\text { Min. Mass } \\
\text { (Da) }\end{array}$ & $\begin{array}{c}\text { Max. Mass } \\
\text { (Da) }\end{array}$ & $\begin{array}{c}\text { No. of MS/MS } \\
\text { Events }\end{array}$ \\
\hline 2 & 34 & 714.18 & 1500.37 & 1426.36 & 2998.73 & 63 \\
3 & 8 & 848.75 & 1176.15 & 2543.23 & 3525.44 & 32 \\
4 & 45 & 714.08 & 1380.06 & 2852.31 & 5516.21 & 143 \\
5 & 39 & 803.49 & 1325.52 & 4012.42 & 6622.58 & 120 \\
6 & 43 & 775.62 & 1458.49 & 4647.67 & 8744.89 & 109 \\
7 & 61 & 747.77 & 1534.29 & 5227.35 & $10,732.96$ & 222 \\
8 & 86 & 787.70 & 1429.84 & 6293.52 & $11,430.63$ & 341 \\
9 & 69 & 700.41 & 1564.79 & 6294.62 & $14,074.01$ & 262 \\
10 & 48 & 756.92 & 1729.69 & 7559.16 & $17,286.78$ & 195 \\
11 & 32 & 726.96 & 1338.87 & 7985.51 & $14,716.50$ & 113 \\
12 & 30 & 710.98 & 1338.68 & 8519.65 & $16,052.07$ & 99 \\
13 & 32 & 762.47 & 1256.51 & 9898.99 & $16,321.52$ & 114 \\
14 & 36 & 732.89 & 1318.67 & $10,246.31$ & $18,447.31$ & 125 \\
15 & 32 & 738.60 & 1099.47 & $11,063.95$ & $16,433.03$ & 109 \\
16 & 29 & 708.10 & 1153.96 & $11,269.49$ & $18,447.30$ & 105 \\
17 & 29 & 737.28 & 1129.03 & $12,516.63$ & $19,176.39$ & 86 \\
18 & 27 & 754.89 & 1163.66 & $13,569.88$ & $20,927.81$ & 96 \\
19 & 37 & 715.21 & 1135.96 & $13,569.85$ & $21,564.03$ & 124 \\
20 & 38 & 710.24 & 1240.59 & $14,184.59$ & $24,791.58$ & 126 \\
21 & 34 & 723.89 & 1185.04 & $15,180.59$ & $24,864.66$ & 106 \\
22 & 28 & 701.95 & 1155.10 & $15,420.70$ & $25,390.00$ & 92 \\
23 & 14 & 711.74 & 1104.83 & $16,346.79$ & $25,387.98$ & 31 \\
24 & 8 & 746.08 & 1036.99 & $17,881.77$ & $24,863.64$ & 18 \\
25 & 3 & 745.98 & 992.59 & $18,624.23$ & $24,789.59$ & 3 \\
\hline & & & & & & \\
\end{tabular}

Overall, precursor charge states ranged from +2 to +25 , parent ions from 700.4094 to $1729.6853 \mathrm{~m} / \mathrm{z}$, and their accurate masses spanned 1426.3553 to $25,389.9953 \mathrm{Da}$. Inherent to MS, the greater the charge state was, the greater the mass of cannabis proteins was (Supplementary Figure S5A). The most abundant precursors bore four to 10 charges, and their accurate masses ranged from 2.8 to $17.3 \mathrm{kDa}$. Therefore, this type of analysis predominantly favoured small proteins from cannabis buds.

Another factor determining precursor selection pertains to protein abundance, emulated by base peak intensity in the mass spectrometer. Indeed, for a protein larger than $20 \mathrm{kDa}$ to undergo MS/MS, its base peak intensity must exceed 2000 counts (Supplementary Figure S5B).

The last factor determining precursor selection relates to protein hydrophobicity, which affects the chromatographic elution. Supplementary Figure S5C reveals that proteins larger than $20 \mathrm{kDa}$ eluted after $75 \mathrm{~min}$ of reverse phase separation; therefore, they must have been more hydrophobic than proteins of smaller size. This means that, for highly hydrophobic proteins, the separation method would need refining by using a different type of stationary phase and/or different mobile phases and gradients.

\subsubsection{The Vast Majority of MS/MS Data from Cannabis Samples Remains Unannotated}

A total of 11,250 MS/MS peak lists were searched against the UniprotKB C. sativa database (663 entries) using the Mascot algorithm, a fragment tolerance of $\pm 50 \mathrm{ppm}$ or $\pm 2 \mathrm{Da}$, and validating the results using a decoy or an error tolerant method (Supplementary Table S1). With a $\pm 50 \mathrm{ppm}$ fragment tolerance, protein N-term acetylation and Met oxidation set as dynamic modifications, and an error tolerant method, 12 proteins were identified [210 (2\%) matches] with 11,040 (98\%) MS/MS spectra 
remaining unassigned and a search time of over $24 \mathrm{~h}$. Using the same parameters but changing error tolerance to decoy brought the number of accessions identified to 21 from 213 (2\%) matched MS/MS spectra and a very fast search time of $29 \mathrm{~s}$ (Table 5). Excessive stringency in Mascot algorithm could justify the low number of database hits [37], as discussed above in the sections pertaining to known protein standards. Relaxing the fragment tolerance to \pm 2 Da listed 36 proteins based on $355(3 \%)$ assigned MS/MS spectra with a search time of $2.5 \mathrm{~min}$. With a $\pm 50 \mathrm{ppm}$ fragment tolerance, protein $\mathrm{N}$-term acetylation, Met oxidation, and phosphorylations of Ser and Tyr residues set as dynamic modifications and a decoy method, the number of unique proteins identified was 21 (187 matches) over a search time of $2 \mathrm{~h}$. Lifting the fragment tolerance to $\pm 2 \mathrm{Da}$ increased the number of hits to 61 proteins with 590 (5\%) MS/MS spectra assigned. Forsaking dynamic modification reduced search times to mere seconds and yielded 20 and 24 identities using $\pm 50 \mathrm{ppm}$ and \pm 2 Da fragment tolerance, respectively (Supplementary Tables S1 and S4).

To further evaluate the effect of Mascot search parameters, a more extensive but less targeted database was interrogated using the least stringent fragment tolerance $( \pm 2 \mathrm{Da})$ and a decoy method. We chose Swissprot, as it is a curated database currently hosting over 200 million sequences. Without any dynamic modification set, searching the whole taxonomy yielded 94 accessions with $998(9 \%)$ MS/MS matches, and searching only viridiplantae taxonomy (39,800 entries) yielded 80 hits [1181 (10\%) matches]. Searching viridiplantae taxonomy and setting protein $\mathrm{N}$-term acetylation and Met oxidation as dynamic modifications listed 141 accessions [1352 (12\%) matches]. Finally, still searching viridiplantae taxonomy but adding phosphorylations of Ser and Tyr residues as dynamic modification generated 274 accessions [1863 (17\%) matches]. The latter search lasted the longest (53 h) (Supplementary Tables S1 and S4). While the list of proteins extends when a larger database is used in conjunction with more relaxed mass tolerances, we do not yet believe in their relevance, as only one protein (Olivetolic acid cyclase, OAC) actually comes from C. sativa species. Previously, Shen and colleagues demonstrate that more decoys fragments (i.e., false positives) are identified when the mass error increases [44]. Furthermore, lower mass accuracy decreases the specificity of identification [37]. For these reasons, we hereafter only focus on the search result obtained from the uniprotKB database with a stringent fragment tolerance $( \pm 50 \mathrm{ppm})$ (Table 5$)$.

We then searched a larger and more specific database containing all the $C$. sativa protein sequences we could retrieve from UniprotKB, NCBI, and MPGR, which amounted to a total of 59,525 accessions. Running the Mascot search with a $50 \mathrm{ppm}$ tolerance and no modifications was very quick (1.2 $\mathrm{min})$ and yielded 31 accessions (Table S1). However, imputing variable modifications significantly augmented the search time. For instance, searching for oxidation (M) and $\mathrm{N}$-term acetylation lasted $1 \mathrm{~h}$ and produced 36 accessions; search for methylation (K) lasted $2 \mathrm{~h}$ and yielded 33 accessions. Anything else turned into day-long searches (Table S1). Setting modifications exponentially increased the search space, thereby exponentially increasing the duration of the search. To overcome this issue, we devised a two steps strategy: (1) In Mascot, we minimized the number of PTMs (none or oxidation M) in order to quickly generate a list of hits. Not including the search outcomes using the second database (Swissprot viridiplantae), a total of 46 unique accessions were identified in medicinal cannabis mature buds bearing numerous PTMs (Table 5); (2) in the Genedata Refiner LC-MS maps of the deconvoluted masses, we explored features in the vicinity of these hits to detect more proteoforms. This allowed the detection of 136 proteoforms (Supplementary Table S5). 
Table 5. List of 46 cannabis proteins identified by top-down proteomics using Mascot algorithm, the first and the third databases, various post-translational modifications (PTMs), $\pm 50 \mathrm{ppm}$ fragment tolerance and ordered by description.

\begin{tabular}{|c|c|c|c|c|c|c|c|c|c|c|}
\hline No. & Accession & Score & Mass (Da) & $\mathrm{RT}(\min )$ & $\begin{array}{c}\text { No. of } \\
\text { Matches }\end{array}$ & Description & Species & Database & Proteoform $^{1}$ & BUP $^{2}$ \\
\hline 1 & A0A0U2H3S7 & 111 & 11721 & 7.5 & 4 & $\begin{array}{l}\text { 30S ribosomal protein S14, } \\
\text { chloroplastic }\end{array}$ & Humulus lupulus & Uniprot & NME, O & no \\
\hline 2 & AKP55264.1 & 111 & 10442 & 40.5 & 1 & $\begin{array}{l}30 \mathrm{~S} \text { ribosomal protein } \mathrm{S} 16, \\
\text { chloroplastic }\end{array}$ & Cannabis sativa & NCBI & \multirow{3}{*}{ NME, NA } & no \\
\hline 3 & csa_locus_3973_iso_2_len_767_ver_2 & 41 & 15430 & 18.8 & 4 & 40 S ribosomal protein S24 & \multirow{2}{*}{$\begin{array}{l}\text { Actinidia chinensis } \\
\text { Dichanthelium } \\
\text { oligosanthes }\end{array}$} & MPGR & & no \\
\hline 4 & csa_locus_3786_iso_3_len_389_ver_2 & 345 & 6796 & 2.9 & 3 & $40 \mathrm{~S}$ ribosomal protein $\mathrm{S} 30$ & & MPGR & & no \\
\hline 5 & A0A0H3W8B6 & 21 & 15440 & 47.5 & 1 & 50S ribosomal protein L16 & Cannabis sativa & Uniprot & M & yes \\
\hline 6 & A0A0C5ARQ5 & 180 & 8020 & 100.3 & 9 & ATP synthase CF0 C subunit & Cannabis sativa & Uniprot & NA, O & no \\
\hline 7 & A0A0C5AUH9 & 62 & 14615 & 75.0 & 3 & \multirow{2}{*}{$\begin{array}{l}\text { ATP synthase CF1 epsilon subunit } \\
\text { ATP synthase epsilon chain, } \\
\text { chloroplastic }\end{array}$} & Cannabis sativa & Uniprot & NME, NA, O & yes \\
\hline 8 & A0A0U2H159 & 54 & 14697 & 75.0 & 3 & & Humulus lupulus & Uniprot & NA, O, D & no \\
\hline 9 & I6XT51 & 80 & 17490 & 52.6 & 6 & Betv1-like protein & Cannabis sativa & Uniprot & $\begin{array}{l}\text { NME, NA, O, } \\
\text { M, P }\end{array}$ & yes \\
\hline 10 & A0A0C5ARS8 & 1641 & 9257 & 96.4 & 29 & Cytochrome b559 subunit alpha & Cannabis sativa & Uniprot & NME, NA & yes \\
\hline 11 & A0A0U2GZT5 & 902 & 9237 & 96.4 & 1 & Cytochrome b559 subunit alpha & Humulus lupulus & Uniprot & NME & yes \\
\hline 12 & A0A0C5AUI2 & 163 & 4392 & 71.9 & 15 & Cytochrome b559 subunit beta & Cannabis sativa & Uniprot & \multirow{3}{*}{ NME } & no \\
\hline 13 & A0A0H3W844 & 24 & 17381 & 99.2 & 1 & Cytochrome b6-f complex subunit 4 & Cannabis sativa & Uniprot & & no \\
\hline 14 & A0A0C5APY4 & 27 & 4195 & 101.1 & 1 & Cytochrome b6-f complex subunit 5 & Cannabis sativa & Uniprot & & no \\
\hline 15 & csa_locus_2489_iso_3_len_603_ver_2 & 20 & 14971 & 35.6 & 2 & Furry & Trema orientale & MPGR & NME, NA & no \\
\hline 16 & csa_locus_15285_iso_1_len_577_ver_2 & 43 & 8673 & 27.6 & 3 & GAG1At protein & Trema orientale & MPGR & $\mathrm{NME}, \mathrm{NA}, \mathrm{O}$ & no \\
\hline 17 & csa_locus_3395_iso_3_len_637_ver_2 & 14 & 10650 & 31.8 & 2 & GroES-like protein & Corchorus capsularis & MPGR & NME, NA & no \\
\hline 18 & csa_locus_4170_iso_1_len_735_ver_2 & 203 & 13905 & 59.9 & 20 & Histone H2A & Morus notabilis & MPGR & NME, A, P & no \\
\hline 19 & csa_locus_3458_iso_4_len_603_ver_2 & 87 & 14959 & 47.1 & 4 & Histone H2B & Cicer arietinum & MPGR & NME, O & no \\
\hline 20 & csa_locus_1853_iso_2_len_1208_ver_2 & 17 & 17895 & 49.2 & 1 & Histone $\mathrm{H} 3.2$ & Triticum aestivum & MPGR & & no \\
\hline 21 & csa_locus_1853_iso_1_len_474_ver_2 & 44 & 15234 & 50.7 & 5 & Histone $\mathrm{H} 3.2$ & Triticum aestivum & MPGR & NME, M, A, P & no \\
\hline 22 & csa_locus_11346_iso_1_len_965_ver_2 & 143 & 15352 & 15.5 & 10 & Histone H3.3 & Meleagris gallopavo & MPGR & $\begin{array}{l}\text { NME, NA, O, } \\
\quad \text { M, A }\end{array}$ & no \\
\hline 23 & csa_locus_61264_iso_2_len_414_ver_2 & 303 & 11322 & 41.5 & 27 & Histone $\mathrm{H} 4$ & $\begin{array}{l}\text { Phanerochaete } \\
\text { chrysosporium }\end{array}$ & MPGR & $\begin{array}{l}\mathrm{NME}, \mathrm{M}, \mathrm{A}, \mathrm{P}, \\
\mathrm{S}\end{array}$ & no \\
\hline 24 & csa_locus_4104_iso_2_len_741_ver_2 & 151 & 17736 & 53.3 & 7 & Major latex/Bet v I type allergen & Parasponia andersonii & MPGR & NME, NA, A & no \\
\hline 25 & csa_locus_2495_iso_2_len_611_ver_2 & 37 & 9659 & 75.0 & 4 & $\begin{array}{l}\text { Mitochondrial outer membrane } \\
\text { translocase complex, subunit Tom }\end{array}$ & Trema orientale & MPGR & $\mathrm{NME}, \mathrm{NA}, \mathrm{O}$ & no \\
\hline 26 & W0U0v5 & 28 & 9563 & 26.2 & 2 & $\begin{array}{l}\text { Non-specific lipid-transfer protein } \\
\text { (Fragment) }\end{array}$ & Cannabis sativa & Uniprot & M & yes \\
\hline 27 & csa_locus_1463_iso_3_len_564_ver_2 & 45 & 7624 & 18.7 & 1 & $\begin{array}{l}\text { Non-specific lipid-transfer protein } \\
\text { AKCS9 }\end{array}$ & Parasponia andersonii & MPGR & & yes \\
\hline 28 & I6WU39 & 174 & 11901 & 65.9 & 11 & Olivetolic acid cyclase & Cannabis sativa & Uniprot & $\begin{array}{l}\text { NME, NA, O, } \\
\text { M, A }\end{array}$ & yes \\
\hline 29 & A0A0C5AS17 & 1538 & 9415 & 31.0 & 39 & Photosystem I iron-sulfur centre & Cannabis sativa & Uniprot & NME, O & yes \\
\hline 30 & $\mathrm{~A} 0 \mathrm{~A} 0 \mathrm{C} 5 \mathrm{AS} 04$ & 15 & 4814 & 98.9 & 2 & $\begin{array}{l}\text { Photosystem I reaction centre } \\
\text { subunit IX }\end{array}$ & Cannabis sativa & Uniprot & $\mathrm{O}, \mathrm{A}$ & no \\
\hline 31 & A0A0C5AS00 & 30 & 4094 & 99.1 & 2 & $\begin{array}{l}\text { Photosystem I reaction centre } \\
\text { subunit VIII }\end{array}$ & Cannabis sativa & Uniprot & $\mathrm{O}, \mathrm{P}$ & no \\
\hline
\end{tabular}


Table 5. Cont

\begin{tabular}{|c|c|c|c|c|c|c|c|c|c|c|}
\hline No. & Accession & Score & Mass (Da) & $\mathrm{RT}(\min )$ & $\begin{array}{l}\text { No. of } \\
\text { Matches }\end{array}$ & Description & Species & Database & Proteoform ${ }^{1}$ & BUP $^{2}$ \\
\hline 32 & А0A0С $5 \mathrm{~B} 2 \mathrm{J7}$ & 1167 & 7515 & 99.6 & 11 & $\begin{array}{l}\text { Photosystem II reaction centre } \\
\text { protein } \mathrm{H}\end{array}$ & Cannabis sativa & Uniprot & NME, O & no \\
\hline 33 & A0A0C5APX7 & 249 & 4193 & 100.1 & 5 & $\begin{array}{c}\text { Photosystem II reaction centre } \\
\text { protein I }\end{array}$ & Cannabis sativa & Uniprot & $\mathrm{NA}, \mathrm{O}, \mathrm{M}$ & no \\
\hline 34 & A0A0C5APY3 & 66 & 4193 & 100.3 & 1 & $\begin{array}{l}\text { Photosystem II reaction centre } \\
\text { protein J }\end{array}$ & Cannabis sativa & Uniprot & NA & no \\
\hline 35 & A0A0H3W8G1 & 25 & 4363 & 99.2 & 2 & $\begin{array}{l}\text { Photosystem II reaction centre } \\
\text { protein L }\end{array}$ & Cannabis sativa & Uniprot & NME & no \\
\hline 36 & A0A0U2DTK8 & 1438 & 3843 & 99.7 & 25 & $\begin{array}{l}\text { Photosystem II reaction centre } \\
\text { protein T }\end{array}$ & Cannabis sativa & Uniprot & & no \\
\hline 37 & A9XV92 & 1243 & 3843 & 99.7 & 18 & $\begin{array}{c}\text { Photosystem II reaction centre } \\
\text { protein T }\end{array}$ & Cannabis sativa & Uniprot & & no \\
\hline 38 & A0A0C5AUI5 & 72 & 7780 & 4.5 & 1 & Ribosomal protein L33 & Cannabis sativa & Uniprot & NME & no \\
\hline 39 & А0A0C5B2H7 & 53 & 11720 & 7.5 & 2 & Ribosomal protein S14 & Cannabis sativa & Uniprot & NME, A & no \\
\hline 40 & A0A0H3W6G0 & 82 & 10443 & 40.5 & 3 & Ribosomal protein S16 & Cannabis sativa & Uniprot & M, A & no \\
\hline 41 & csa_locus_3039_iso_2_len_611_ver_2 & 125 & 9779 & 42.5 & 5 & $\begin{array}{l}\text { Small zinc finger/mitochondrial } \\
\text { import inner membrane translocase } \\
\text { subunit TIM10-like }\end{array}$ & Juglans regia & MPGR & $\begin{array}{l}\text { NME, NA, O, } \\
\text { A }\end{array}$ & no \\
\hline 42 & csa_locus_13354_iso_1_len_537_ver_2 & 31 & 9073 & 55.7 & 2 & $\begin{array}{l}\text { Small zinc finger/Tim10/DDP family } \\
\text { zinc finger }\end{array}$ & Parasponia andersonii & MPGR & $\mathrm{O}$ & no \\
\hline 43 & csa_locus_2526_iso_1_len_396_ver_2 & 227 & 6442 & 54.2 & 10 & $\begin{array}{l}\text { Ubiquinol-cytochrome c reductase } \\
\text { complex } 6.7 \mathrm{kDa} \text { protein }\end{array}$ & Trema orientale & MPGR & NME & no \\
\hline 44 & csa_locus_5849_iso_5_len_634_ver_2 & 178 & 13600 & 31.1 & 4 & Uncharacterized protein & Fagus sylvatica & MPGR & NME, NA, A & no \\
\hline 45 & csa_locus_6096_iso_1_len_715_ver_2 & 21 & 7326 & 45.4 & 1 & Uncharacterized protein & Trema orientale & MPGR & NME & no \\
\hline 46 & csa_locus_3129_iso_3_len_709_ver_2 & 17 & 11165 & 34.2 & 2 & Uncharacterized protein & Aquilegia coerulea & MPGR & NME, NA & no \\
\hline
\end{tabular}

acetylation (K), P for por as NME for N-term M exlised, O for oxidation (M), NA for N-term acetylation, M for methylation (K), D for dimethylation (K), S for succinylation (K), A for

Plant Genomic Resource. ${ }^{2}$ Proteins identified by BUP pin [1]. 
NCBI yielded one (2\%) accession (AKP55264.130S ribosomal protein S16, chloroplastic), MPGR yielded $20(43 \%)$ accessions, and UniprotKB yielded 25 (55\%) accessions. This suggests that, even though UniprotKB hosts the smallest number of $C$. sativa accessions (663) relative to NCBI (1451) and MPGR $(57,411)$, it generated the highest number of identities, a testament to UniprotKB quality and well-deserved status of reference database for proteins. The masses of the 46 identified proteins ranged from $3.8 \mathrm{kD}$ to $17.9 \mathrm{kD}$. Twenty accessions had a Mascot score above 100, and 36 accessions were identified using more than one MS/MS spectrum (Table 5 and Supplementary Table S5). No missed cleavage was found $(M>0)$, possibly explaining the low number of identified proteins, as we were expecting natural protein degradation to occur. The protein identified with the highest score was cytochrome b559 subunit alpha (accession A0A0C5ARS8, score of 1641, 29 matches, Supplementary Figure S6). Only nine (20\%) of the intact proteins identified by TDP were also identified in our BUP study [1], which highlights the complementarity of both approaches.

As previously observed on the protein standards, fragmentation efficiency of cannabis intact proteins depends on the charge state of the parent ion, on the type of MS/MS mode, and on the level of energy applied. We illustrated this using the protein exhibiting the second highest Mascot score (1664), Photosystem I iron-sulfur centre (PS I Fe-S centre, accession A0A0C5AS17), identified with 39 MS/MS spectra. Fragmentation efficiency was assessed using the ProSight Lite program by the percentage of inter-residue cleavages achieved. MS/MS spectra differed in the number of peaks and their distribution along the mass range (Figure 6A,B).

The optimum dissociation of a precursor ion with high charge state $(857.31 \mathrm{~m} / \mathrm{z}, \mathrm{z}=+11)$ was achieved with ETD at "mid" energy, whereas a precursor ion of comparable intensity but with lower charge state (1178.55 $\mathrm{m} / \mathrm{z}, \mathrm{z}=+8)$ responded better to CID and HCD at "low" and "high" energy levels, respectively. All MS/MS data considered, fragmenting $857.31 \mathrm{~m} / \mathrm{z}$ and $1178.55 \mathrm{~m} / \mathrm{z}$ parent ions yielded $70 \%$ and $65 \%$ inter-residue cleavages, respectively, and $82 \%$ all together (Figure $6 \mathrm{C}$ ). In order to maximise AA sequence coverage, it was essential to multiply the MS/MS conditions on as many precursor ions as possible. This, of course, limited the total number of different proteins analysed in a top-down approach. Coupling this strategy with an extended separation run should alleviate this drawback.

Most of the identified proteins (17/46, 37\%) were involved in photosynthesis (subunits of cytochromes and photosystems I and II, as well as chloroplastic ATPases), then in protein translation (eight ribosomal proteins, 17\%). Also identified were six histones. Only one protein belonged to the phytocannabinoid biosynthesis, olivetolic acid cyclase (I6WU39, OAC), previously identified by BUP $[1,17]$. With 46 identities, this TDP experiment identified fewer individual proteins than our previous shotgun study, which produced 160 accessions using a database from UniproKB [1]; however, the power of TDP lies in the detection of proteoforms of the identified proteins (Table 5 and Supplementary Table S5). In particular, the $\mathrm{N}$-terminus excision of the initial M (NME, Table 5) was determined for $28(61 \%)$ accessions. This valuable and novel information is not found in public databases such as UniprotKB. The PTMs identified in this work were methylation (K), dimethylation $(\mathrm{K})$, acetylation (N-term and $\mathrm{K})$, succinylation $(\mathrm{K})$, phosphorylation $(\mathrm{STY})$, as well as oxidation $(\mathrm{M})$. Seventeen $(37 \%)$ proteoformes were oxidized (O, Table 5). Our experimental design did not allow for distinguishing between in vivo protein oxidation and artefactual oxidation occurring during sample preparation. Ursem and colleagues demonstrated that centrifugation, freeze-thaw cycles, or long-term storage at $-20^{\circ} \mathrm{C}$ or $-80^{\circ} \mathrm{C}$ did not oxidise proteins [47]. The authors did not test the effect of sample agitation such as vortexing, for instance, whereby aerating the sample can trigger spontaneous oxidation. This might have occurred in our experiment. If needed, a method is available to eliminate this analytical artefact [48]. Limiting the number of steps in sample preparation lowers the chance of artefactual oxidation. A critical review of this approach has been undertaken and documented [49]. 


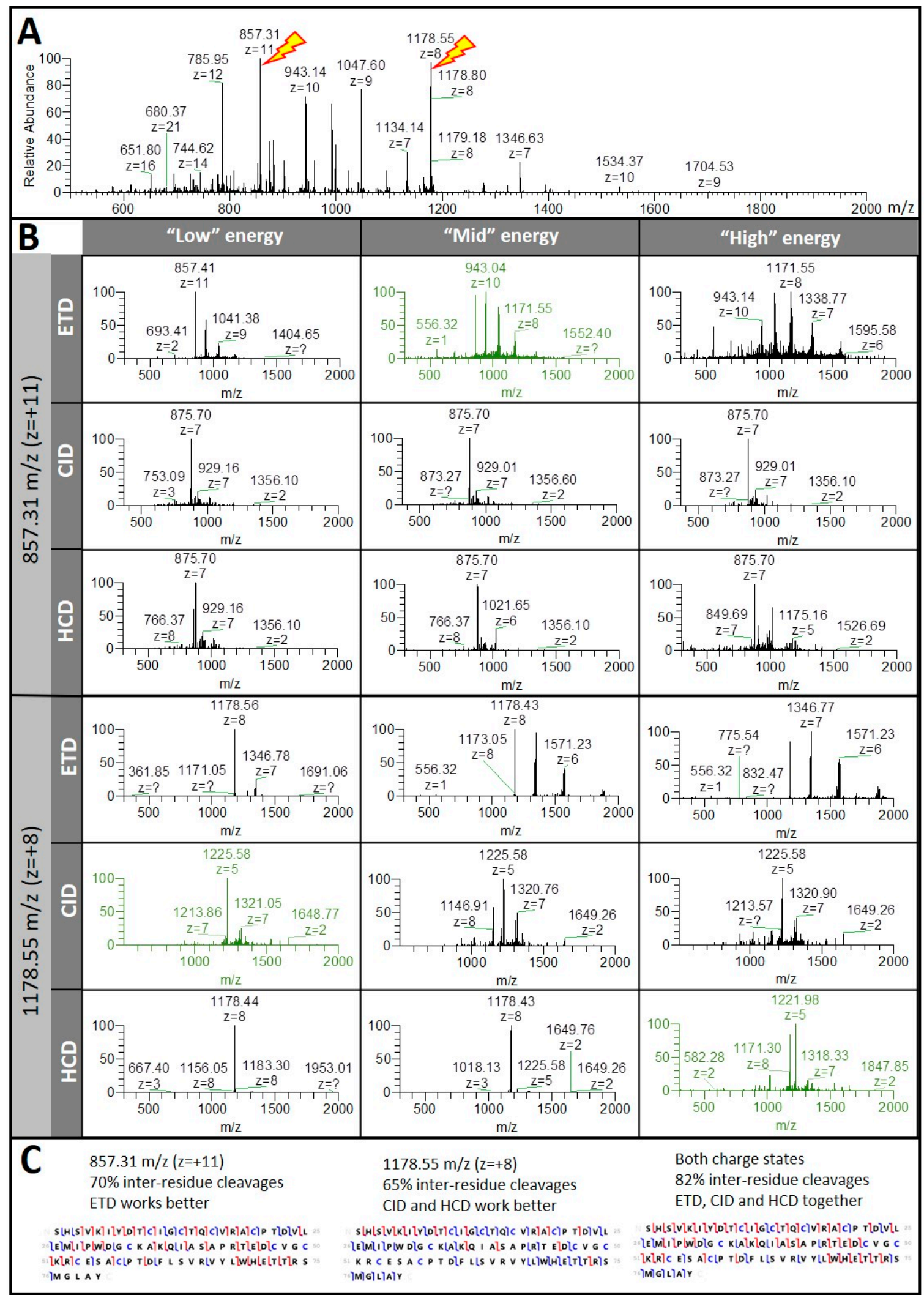

Figure 6. Top-down sequencing summary for C. sativa Photosystem I iron-sulfur centre (PS I Fe-S centre, accession A0A0C5AS17). (A) FTMS spectra at $30.8 \mathrm{~min}$, lightning bolts depicts the two most abundant charge states chosen for MS/MS fragmentation; (B) FTMS/MS spectra for both charge states using each of the three MS/MS methods; spectra in green represent the energy level for a particular MS/MS mode that yielded the best sequencing information; (C) AA sequence coverage for each of the charge states and then combined. 
Eighteen (39\%) proteoforms bore an N-terminus acetylation (NA, Table 5). N-terminal acetylation corresponded to the appending of an acetyl group to the $\mathrm{N}$-terminal amino group in an irreversible manner, which impacted the lifespan, the folding characteristics, and the binding properties of the acetylated protein [50]. This is a widespread protein modification across all taxa, and C. sativa is no exception, as demonstrated in this work. Another fairly frequent PTM in our dataset was the methylation of $\mathrm{K}$ residues reported in eight (17\%) protein accessions (M, Table 5). The post-translational methylation of $\mathrm{K}$ residues catalysed by lysine (K)-specific protein methyltransferases (KMTs) is a very common and important protein modification [51] and is particularly well documented for histones with respect to DNA processing [52]. While we did not identify any KMTs by BUP [1], we suspect they are present and highly active in cannabis buds, given the frequency of methylated proteoforms (Table 5). We identified four accessions with phosphorylations ( $\mathrm{P}$, Table 5). Phosphoproteins are ubiquitous to all kingdoms; they have been well documented in human, mice, and yeast but much less in Arabidopsis [53], the reference plant. Plants contain glycoproteins; only a few reports have applied MS to profile intact plant N-glycoproteins, and their analysis involves specific technical steps, such as the deglycosylation of glycoproteins and their recovery by lectin-affinity columns [54], which were not attempted here. However, this warrants future investigation.

Examples of proteoforms detected in this TDP study are given in Figure 7.
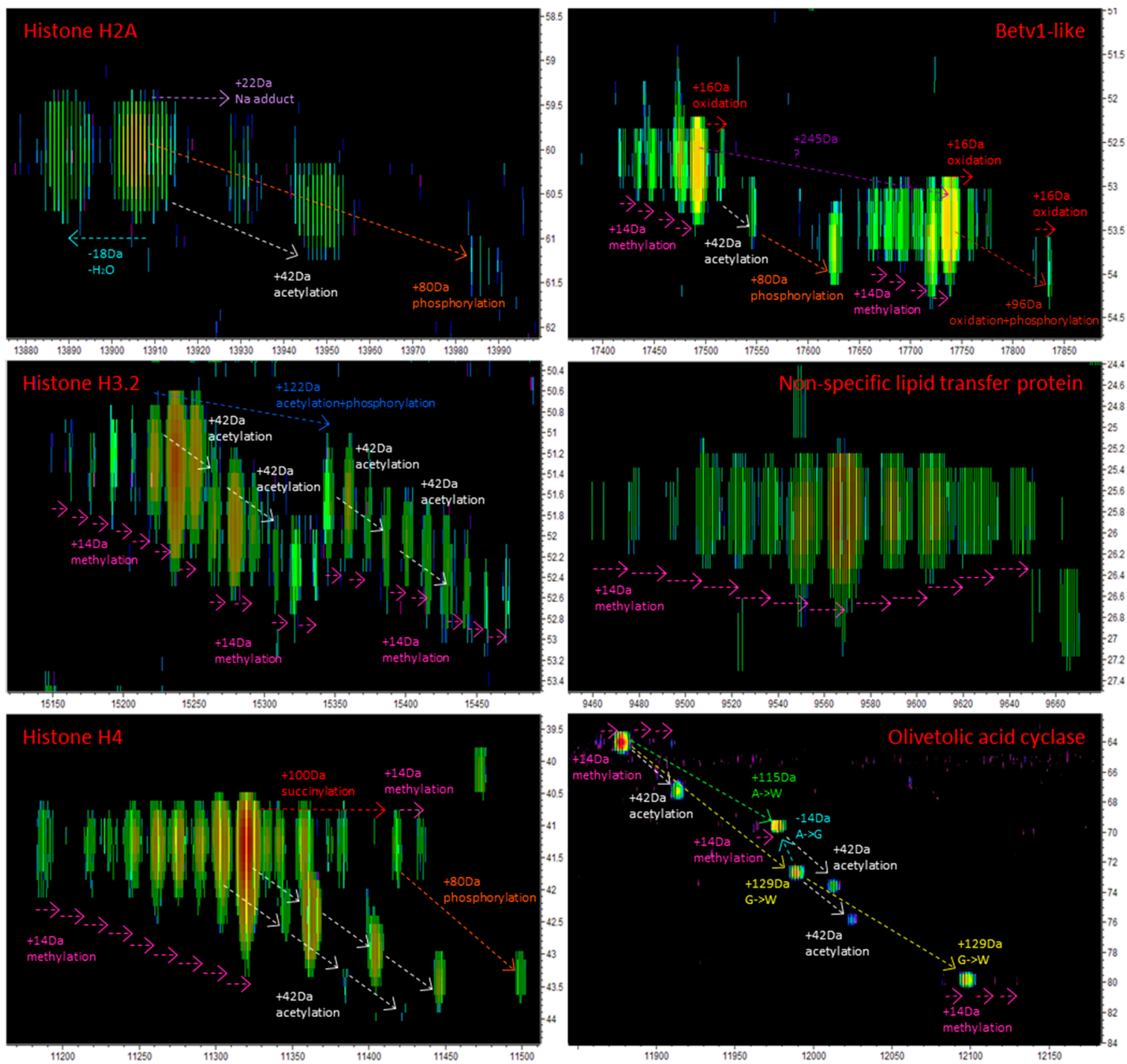

Figure 7. Examples of PTMs of cannabis proteins identified by top-down proteomics (TDP). 
Histones were heavily modified [55]—in particular, they were heavily methylated [52]—which we demonstrate in Figure 7 on histones H3.2 and H4. Histones were also acetylated and phosphorylated [56], as shown for histones H2A, H3.2, and H4 (Figure 7). We also found a succinylated proteoform of histone H4. A non-specific lipid transfer protein (nsLTP) also exhibited several methylated states (Figure 7), which has never been shown before. Due to their high allergenicity and cross-reactivity, nsLTPs are major allergens of $C$. sativa [57]. Perhaps some methylated proteoforms of nsLTP are more allergenic than other. Bet v1-like protein (UniprotKB accession I6XT51) is similar to the major pollen allergen Bet $\mathrm{v}$ 1. In our sample, we found this protein to be methylated, acetylated, oxidized, and phosphorylated (Figure 7). We also observed that the same group of proteoforms shifted by $245 \mathrm{Da}$, which we could not assign to any obvious modification. With a Mascot score of 174, OAC was identified without its initial $\mathrm{M}$ residue, which has not been evidenced before. Several methylated and acetylated proteoforms of OAC WEre identified (Supplementary Table S5 and Figure 7), along with a possible allelic variant (Figure 7). However, the latter must be confirmed by top-down sequencing.

\section{Conclusions}

This was the first top-down MS proteomics study on medicinal cannabis reproductive tissues. In this work, we tested various MS/MS parameters first on known proteins and then on intact denatured proteins from cannabis buds. Protein fragmentation efficiency depends on the type of MS/MS mode, the level of energy applied, and the charge state of the precursor ion. While some conditions proved less optimal, they still yielded complementary sequencing information. Consequently, the more MS/MS data were acquired for a given protein, the greater the AA sequence coverage was. The biggest limitation was the size of the protein with greater sequence coverage observed for smaller molecules. Data analysis proved challenging, and most of the MS/MS spectra remained unannotated for a reason yet to be elucidated. Prosight Lite program yielded the most exhaustive sequencing information but only operates on known proteins. We found that the best strategy to explore cannabis top-down data was to first search MS/MS data using Mascot with a limited number of PTMs and stringent tolerances followed by the exploration of LC-MS deconvoluted maps in Genedata Refiner to further detect proteoforms. Future work will involve further fine-tuning of the data processing and applying this top-down strategy to different cultivars of medicinal cannabis with the hope of discovering more allelic variations and PTMs.

Supplementary Materials: The following are available online http://www.mdpi.com/2227-7382/7/4/33/s1, Figure S1: Relationship between the molecular weight (MW) of the protein standards analysed and their sequencing results by top-down proteomics, Figure S2: Mascot search results of protein standards MS/MS peak lists using (A) a homemade database and (B) Swissprot database, Figure S3: Distribution of cannabis proteins according to their accurate masses (3-70 kDa), Figure S4: Multivariate statistical analyses using LC-MS data from cannabis protein samples. (A) Principal Component Analysis (PCA); (B) Hierarchical Clustering Analysis (HCA), Figure S5: Statistics on parent ions from cannabis proteins analysed by LC-MS/MS. (A) Distribution of deconvoluted mass according to their charge state; (B) Distribution of deconvoluted masses according to their base peak intensity; (C) Distribution of deconvoluted masses according to their elution times, Figure S6: Top-down sequencing result from Mascot for C. sativa Cytochrome b559 subunit alpha (A0A0C5ARS8). (A) Protein view; (B) Peptide view, Table S1: Summary of Mascot results for standards and cannabis samples using various databases, dynamic modifications, and fragment tolerance, Table S2: List of proteins identified from standards samples using Mascot algorithm and either a homemade database or Swissprot database, Table S3: List of proteoforms identified from standards samples using Mascot algorithm and either a homemade database or Swissprot database, Table S4: List of proteins identified from medicinal cannabis protein samples using Mascot algorithm and UniProtKB Cannabis sativa or SwissProt databases, Table S5: List of proteoforms identified from protein standards samples using Mascot algorithm with $50 \mathrm{ppm}$ fragment tolerance and UniProtKB C. sativa database.

Author Contributions: Conceptualization, D.V.; methodology, D.V., S.B.; software, D.V., S.B.; validation, D.V.; formal analysis, D.V.; resources, S.R., G.S.; data curation, D.V.; writing—original draft preparation, D.V.; review and editing, D.V., S.B., S.R., G.S.; visualization, D.V.; supervision, S.R.; project administration, G.S.; funding acquisition, G.S.

Funding: This research received no external funding.

Acknowledgments: The authors would like to acknowledge John Cottrell from Matrix Science for his advices on which parameters to use in Mascot program. 
Conflicts of Interest: The authors declare no conflict of interest.

\section{References}

1. Vincent:, D.; Rochfort, S.; Spangenberg, G. Optimisation of Protein Extraction from Medicinal Cannabis Mature Buds for Bottom-Up Proteomics. Molecules 2019, 24, 659. [CrossRef] [PubMed]

2. Elkins, A.C.; Deseo, M.A.; Rochfort, S.; Ezernieks, V.; Spangenberg, G. Development of a validated method for the qualitative and quantitative analysis of cannabinoids in plant biomass and medicinal cannabis resin extracts obtained by super-critical fluid extraction. J. Chromatogr. B Analyt. Technol. Biomed. Life Sci. 2019, 1109, 76-83. [CrossRef] [PubMed]

3. Asati, A.K.; Sahoo, H.B.; Sahu, S.; Dwivedi, A. Phytochemical and pharmacological profile of Cannabis sativa L. Int. J. Ind. Herbs Drugs 2017, 2, 37-45.

4. ElSohly, M.A.; Radwan, M.M.; Gul, W.; Chandra, S.; Galal, A. Phytochemistry of Cannabis sativa L. Prog. Chem. Org. Nat. Prod. 2017, 103, 1-36. [CrossRef] [PubMed]

5. McPartland, J.M. Cannabis Systematics at the Levels of Family, Genus, and Species. Cannabis Cannabinoid Res. 2018, 3.1, 203-212. [CrossRef] [PubMed]

6. Adams, R.; Hunt, M.; Clark, J.H. Structure of cannabidiol, a product isolated from the marihuana extract of Minnesota wild hemp. J. Am. Chem. Soc. 1940, 62, 196-200. [CrossRef]

7. ElSohly, M.A.; Slade, D. Chemical constituents of marijuana: The complex mixture of natural cannabinoids. Life Sci. 2005, 78, 539-548. [CrossRef] [PubMed]

8. Mechoulam, R.; Gaoni, Y. Recent advances in the chemistry of hashish. In Progress in the Chemistry of Organic Natural Products; Springer: Vienna, Austria, 1967; Volume 25, pp. 175-213.

9. Andre, C.M.; Hausman, J.-F.; Guerriero, G. Cannabis sativa: The Plant of the Thousand and One Molecules. Front. Plant. Sci. 2016, 7, 19. [CrossRef] [PubMed]

10. Sirikantaramas, S.; Taura, F.; Morimoto, S.; Shoyama, Y. Recent advances in Cannabis sativa research: Biosynthetic studies and its potential in biotechnology. Curr. Pharm. Biotechnol. 2007, 8, 237-243. [CrossRef] [PubMed]

11. Bona, E.; Marsano, F.; Cavaletto, M.; Berta, G. Proteomic characterization of copper stress response in Cannabis sativa roots. Proteomics 2007, 7, 1121-1130. [CrossRef] [PubMed]

12. Behr, M.; Sergeant, K.; Leclercq, C.C.; Planchon, S.; Guignard, C.; Lenouvel, A.; Renaut, J.; Hausman, J.F.; Lutts, S.; Guerriero, G. Insights into the molecular regulation of monolignol-derived product biosynthesis in the growing hemp hypocotyl. BMC Plant. Biol. 2018, 18, 1. [CrossRef] [PubMed]

13. Xia, C.; Hong, L.; Yang, Y.; Yanping, X.; Xing, H.; Gang, D. Protein Changes in Response to Lead Stress of Lead-Tolerant and Lead-Sensitive Industrial Hemp Using SWATH Technology. Genes 2019, 10, 396. [CrossRef] [PubMed]

14. Aiello, G.; Fasoli, E.; Boschin, G.; Lammi, C.; Zanoni, C.; Citterio, A.; Arnoldi, A. Proteomic characterization of hempseed (Cannabis sativa L.). J. Proteom. 2016, 147, 187-196. [CrossRef] [PubMed]

15. Park, S.K.; Seo, J.B.; Lee, M.Y. Proteomic profiling of hempseed proteins from Cheungsam. Biochim. Biophys. Acta 2012, 1824, 374-382. [CrossRef] [PubMed]

16. Raharjo, T.J.; Widjaja, I.; Roytrakul, S.; Verpoorte, R. Comparative proteomics of Cannabis sativa plant tissues. J. Biomol. Tech. 2004, 15, 97-106. [PubMed]

17. Happyana, N. Metabolomics, Proteomics, and Transcriptomics of Cannabis sativa L. Trichomes. PhD Thesis, University in Dortmund, Dortmund, Germany, 2014.

18. Jenkins, C.; Orsburn, B. Constructing a Draft Map of the Cannabis Proteome. Biorxiv 2019. [CrossRef]

19. Toby, T.K.; Fornelli, L.; Kelleher, N.L. Progress in Top-Down Proteomics and the Analysis of Proteoforms. Annu. Rev. Anal. Chem. 2016, 9, 499-519. [CrossRef]

20. Schaffer, L.V.; Millikin, R.J.; Miller, R.M.; Anderson, L.C.; Fellers, R.T.; Ge, Y.; Kelleher, N.L.; LeDuc, R.D.; Liu, X.; Payne, S.H.; et al. Identification and Quantification of Proteoforms by Mass Spectrometry. Proteomics 2019, 19, e1800361. [CrossRef]

21. Kelleher, N.L. Top-down proteomics. Anal. Chem. 2004, 76, 197A-203A. [CrossRef]

22. Dang, X.; Scotcher, J.; Wu, S.; Chu, R.K.; Tolic, N.; Ntai, I.; Thomas, P.M.; Fellers, R.T.; Early, B.P.; Zheng, Y.; et al. The first pilot project of the consortium for top-down proteomics: A status report. Proteomics 2014, 14, 1130-1140. [CrossRef] [PubMed] 
23. LeDuc, R.D.; Schwammle, V.; Shortreed, M.R.; Cesnik, A.J.; Solntsev, S.K.; Shaw, J.B.; Martin, M.J.; Vizcaino, J.A.; Alpi, E.; Danis, P.; et al. ProForma: A Standard Proteoform Notation. J. Proteome Res. 2018, 17, 1321-1325. [CrossRef] [PubMed]

24. Donnelly, D.P.; Rawlins, C.M.; DeHart, C.J.; Fornelli, L.; Schachner, L.F.; Lin, Z.; Lippens, J.L.; Aluri, K.C.; Sarin, R.; Chen, B.; et al. Best practices and benchmarks for intact protein analysis for top-down mass spectrometry. Nat. Methods 2019, 16, 587-594. [CrossRef] [PubMed]

25. Shliaha, P.V.; Gibb, S.; Gorshkov, V.; Jespersen, M.S.; Andersen, G.R.; Bailey, D.; Schwartz, J.; Eliuk, S.; Schwammle, V.; Jensen, O.N. Maximizing Sequence Coverage in Top-Down Proteomics By Automated Multimodal Gas-Phase Protein Fragmentation. Anal. Chem. 2018, 90, 12519-12526. [CrossRef] [PubMed]

26. Fornelli, L.; Toby, T.K.; Schachner, L.F.; Doubleday, P.F.; Srzentic, K.; DeHart, C.J.; Kelleher, N.L. Top-down proteomics: Where we are, where we are going? J. Proteom. 2018, 175, 3-4. [CrossRef] [PubMed]

27. Raynes, J.K.; Vincent, D.; Zawadzki, J.L.; Savin, K.; Mertens, D.; Logan, A.; Williams, R.P.W. Investigation of Age Gelation in UHT Milk. Beverages 2018, 4, 95. [CrossRef]

28. Vincent, D.; Elkins, A.; Condina, M.R.; Ezernieks, V.; Rochfort, S. Quantitation and Identification of Intact Major Milk Proteins for High-Throughput LC-ESI-Q-TOF MS Analyses. PLoS ONE 2016, 11, e0163471. [CrossRef] [PubMed]

29. Vincent, D.; Mertens, D.; Rochfort, S. Optimisation of Milk Protein Top-Down Sequencing Using In-Source Collision-Induced Dissociation in the Maxis Quadrupole Time-of-Flight Mass Spectrometer. Molecules 2018, 23, 2777. [CrossRef]

30. Vincent, D.; Ezernieks, V.; Elkins, A.; Nguyen, N.; Moate, P.J.; Cocks, B.G.; Rochfort, S. Milk Bottom-Up Proteomics: Method Optimization. Front. Genet. 2015, 6, 360. [CrossRef]

31. DeHart, C.J.; Fellers, R.T.; Fornelli, L.; Kelleher, N.L.; Thomas, P.M. Bioinformatics Analysis of Top-Down Mass Spectrometry Data with ProSight Lite. Methods Mol. Biol. 2017, 1558, 381-394. [CrossRef] [PubMed]

32. Drabik, A.; Bodzon-Kulakowska, A.; Suder, P. Application of the ETD/PTR reactions in top-down proteomics as a faster alternative to bottom-up nanoLC-MS/MS protein identification. J. Mass Spectrom. 2012, 47, 1347-1352. [CrossRef] [PubMed]

33. Riley, N.M.; Mullen, C.; Weisbrod, C.R.; Sharma, S.; Senko, M.W.; Zabrouskov, V.; Westphall, M.S.; Syka, J.E.; Coon, J.J. Enhanced Dissociation of Intact Proteins with High Capacity Electron Transfer Dissociation. J. Am. Soc. Mass Spectrom. 2016, 27, 520-531. [CrossRef] [PubMed]

34. Riley, N.M.; Westphall, M.S.; Coon, J.J. Activated Ion-Electron Transfer Dissociation Enables Comprehensive Top-Down Protein Fragmentation. J. Proteome Res. 2017, 16, 2653-2659. [CrossRef] [PubMed]

35. Weisbrod, C.R.; Kaiser, N.K.; Syka, J.E.P.; Early, L.; Mullen, C.; Dunyach, J.J.; English, A.M.; Anderson, L.C.; Blakney, G.T.; Shabanowitz, J.; et al. Front-End Electron Transfer Dissociation Coupled to a 21 Tesla FT-ICR Mass Spectrometer for Intact Protein Sequence Analysis. J. Am. Soc. Mass Spectrom. 2017, 28, 1787-1795. [CrossRef] [PubMed]

36. Fort, K.L.; Cramer, C.N.; Voinov, V.G.; Vasil'ev, Y.V.; Lopez, N.I.; Beckman, J.S.; Heck, A.J.R. Exploring ECD on a Benchtop Q Exactive Orbitrap Mass Spectrometer. J. Proteome Res. 2018, 17, 926-933. [CrossRef] [PubMed]

37. Karabacak, N.M.; Li, L.; Tiwari, A.; Hayward, L.J.; Hong, P.; Easterling, M.L.; Agar, J.N. Sensitive and specific identification of wild type and variant proteins from 8 to $669 \mathrm{kDa}$ using top-down mass spectrometry. Mol. Cell Proteom. 2009, 8, 846-856. [CrossRef] [PubMed]

38. Zubarev, R. Protein primary structure using orthogonal fragmentation techniques in Fourier transform mass spectrometry. Expert Rev. Proteom. 2006, 3, 251-261. [CrossRef] [PubMed]

39. Cobb, J.S.; Easterling, M.L.; Agar, J.N. Structural characterization of intact proteins is enhanced by prevalent fragmentation pathways rarely observed for peptides. J. Am. Soc. Mass Spectrom. 2010, 21, 949-959. [CrossRef]

40. Macek, B.; Waanders, L.F.; Olsen, J.V.; Mann, M. Top-down protein sequencing and MS3 on a hybrid linear quadrupole ion trap-orbitrap mass spectrometer. Mol. Cell Proteom. 2006, 5, 949-958. [CrossRef] [PubMed]

41. Liu, Z.; Schey, K.L. Fragmentation of multiply-charged intact protein ions using MALDI TOF-TOF mass spectrometry. J. Am. Soc. Mass Spectrom. 2008, 19, 231-238. [CrossRef] [PubMed]

42. Suckau, D.; Resemann, A. T3-sequencing: Targeted characterization of the N- and C-termini of undigested proteins by mass spectrometry. Anal. Chem. 2003, 75, 5817-5824. [CrossRef] [PubMed] 
43. Sellami, L.; Belgacem, O.; Villard, C.; Openshaw, M.E.; Barbier, P.; Lafitte, D. In-source decay and pseudo tandem mass spectrometry fragmentation processes of entire high mass proteins on a hybrid vacuum matrix-assisted laser desorption ionization-quadrupole ion-trap time-of-flight mass spectrometer. Anal. Chem. 2012, 84, 5180-5185. [CrossRef] [PubMed]

44. Shen, Y.; Tolic, N.; Purvine, S.O.; Smith, R.D. Improving CID, HCD, and ETD FT MS/MS degradome-peptidome identifications using high accuracy mass information. J. Proteome Res. 2012, 11, 668-677. [CrossRef] [PubMed]

45. Geer, L.Y.; Markey, S.P.; Kowalak, J.A.; Wagner, L.; Xu, M.; Maynard, D.M.; Yang, X.; Shi, W.; Bryant, S.H. Open mass spectrometry search algorithm. J. Proteome Res. 2004, 3, 958-964. [CrossRef] [PubMed]

46. Liu, X.; Sirotkin, Y.; Shen, Y.; Anderson, G.; Tsai, Y.S.; Ting, Y.S.; Goodlett, D.R.; Smith, R.D.; Bafna, V.; Pevzner, P.A. Protein identification using top-down. Mol. Cell Proteom. 2012, 11, M111-008524. [CrossRef] [PubMed]

47. Ursem, S.R.; Vervloet, M.G.; Hillebrand, J.J.G.; de Jongh, R.T.; Heijboer, A.C. Oxidation of PTH: In vivo feature or effect of preanalytical conditions? Clin. Chem. Lab. Med. 2018, 56, 249-255. [CrossRef] [PubMed]

48. Liu, H.; Ponniah, G.; Neill, A.; Patel, R.; Andrien, B. Accurate determination of protein methionine oxidation by stable isotope labeling and LC-MS analysis. Anal. Chem. 2013, 85, 11705-11709. [CrossRef]

49. Rogowska-Wrzesinska, A.; Wojdyla, K.; Nedic, O.; Baron, C.P.; Griffiths, H.R. Analysis of protein carbonylation-pitfalls and promise in commonly used methods. Free Radic. Res. 2014, 48, 1145-1162. [CrossRef]

50. Ree, R.; Varland, S.; Arnesen, T. Spotlight on protein N-terminal acetylation. Exp. Mol. Med. 2018, 50, 90. [CrossRef]

51. Falnes, P.O.; Jakobsson, M.E.; Davydova, E.; Ho, A.; Malecki, J. Protein lysine methylation by seven-beta-strand methyltransferases. Biochem. J. 2016, 473, 1995-2009. [CrossRef]

52. Gong, F.; Miller, K.M. Histone methylation and the DNA damage response. Mutat. Res. 2019, 780, 37-47. [CrossRef] [PubMed]

53. Vlastaridis, P.; Kyriakidou, P.; Chaliotis, A.; Van de Peer, Y.; Oliver, S.G.; Amoutzias, G.D. Estimating the total number of phosphoproteins and phosphorylation sites in eukaryotic proteomes. Gigascience 2017, 6, 1-11. [CrossRef] [PubMed]

54. Zeng, W.; Ford, K.L.; Bacic, A.; Heazlewood, J.L. N-linked Glycan Micro-heterogeneity in Glycoproteins of Arabidopsis. Mol. Cell Proteom. 2018, 17, 413-421. [CrossRef] [PubMed]

55. Castillo, J.; Lopez-Rodas, G.; Franco, L. Histone Post-Translational Modifications and Nucleosome Organisation in Transcriptional Regulation: Some Open Questions. Adv. Exp. Med. Biol. 2017, 966, 65-92. [CrossRef] [PubMed]

56. Manning, L.R.; Manning, J.M. Contributions to nucleosome dynamics in chromatin from interactive propagation of phosphorylation/acetylation and inducible histone lysine basicities. Protein Sci. 2018, 27, 662-671. [CrossRef] [PubMed]

57. Decuyper, I.I.; Rihs, H.P.; Van Gasse, A.L.; Elst, J.; De Puysseleyr, L.; Faber, M.A.; Mertens, C.; Hagendorens, M.M.; Sabato, V.; Bridts, C.; et al. Cannabis allergy: What the clinician needs to know in 2019. Expert Rev. Clin. Immunol. 2019, 15, 599-606. [CrossRef] [PubMed]

(C) 2019 by the authors. Licensee MDPI, Basel, Switzerland. This article is an open access article distributed under the terms and conditions of the Creative Commons Attribution (CC BY) license (http://creativecommons.org/licenses/by/4.0/). 